University of South Florida

DIGITAL COMMONS

Digital Commons @ University of

@ UNIVERSITY OF SOUTH FLORIDA

South Florida

$9-2016$

\title{
A Hybrid Method to Estimate Suspended Particle Sizes from Satellite Measurements over Bohai Sea and Yellow Sea
}

\author{
Deyong Sun \\ Nanjing University of Information Science and Technology \\ Zhongfeng Qiu \\ Nanjing University of Information Science and Technology \\ Chuanmin $\mathrm{Hu}$ \\ University of South Florida, huc@usf.edu \\ Shengqiang Wang \\ Nanjing University of Information Science and Technology \\ Lin Wang \\ National Marine Environment Monitoring Center
}

See next page for additional authors

Follow this and additional works at: https://digitalcommons.usf.edu/msc_facpub

Part of the Life Sciences Commons

\section{Scholar Commons Citation}

Sun, Deyong; Qiu, Zhongfeng; Hu, Chuanmin; Wang, Shengqiang; Wang, Lin; Zheng, Lufei; Peng, Tian; and He, Yijun, "A Hybrid Method to Estimate Suspended Particle Sizes from Satellite Measurements over Bohai Sea and Yellow Sea" (2016). Marine Science Faculty Publications. 1952.

https://digitalcommons.usf.edu/msc_facpub/1952

This Article is brought to you for free and open access by the College of Marine Science at Digital Commons @ University of South Florida. It has been accepted for inclusion in Marine Science Faculty Publications by an authorized administrator of Digital Commons @ University of South Florida. For more information, please contact digitalcommons@usf.edu. 


\section{Authors}

Deyong Sun, Zhongfeng Qiu, Chuanmin Hu, Shengqiang Wang, Lin Wang, Lufei Zheng, Tian Peng, and Yijun He 


\section{Journal of Geophysical Research: Oceans}

\section{RESEARCH ARTICLE \\ 10.1002/2016JC011949 \\ A hybrid method to estimate suspended particle sizes from satellite measurements over Bohai Sea and Yellow Sea}

Key Points:

- Establishing a close linkage between particle sizes with specific

backscattering

- Proposing a new hybrid method to estimate particle sizes from satellite measurement

- Successful application of the new method to MODIS data

Correspondence to:

Z. Qiu,

zhongfeng.qiu@nuist.edu.cn and

D. Sun,

sundeyong1984@163.com

Citation:

Sun, D., Z. Qiu, C. Hu, S. Wang, L. Wang, L. Zheng, T. Peng, and Y. He (2016), A

hybrid method to estimate suspended particle sizes from satellite measurements over Bohai Sea and Yellow Sea, J. Geophys. Res. Oceans, 121, 6742-6761, doi:10.1002/ 2016JC011949.

\section{Received 9 MAY 2016} Accepted 26 AUG 2016 Accepted article online 29 AUG 2016 Published online 10 SEP 2016 (c) 2016. American Geophysical Union. All Rights Reserved.

\author{
Deyong Sun 1,2, Zhongfeng Qiu1,2, Chuanmin Hư3, Shengqiang Wang 1,2, Lin Wang4, Lufei Zheng ${ }^{1}$, \\ Tian Peng ${ }^{1}$, and Yijun $\mathrm{He}^{1,2}$
}
${ }^{1}$ School of Marine Sciences, Nanjing University of Information Science and Technology, Nanjing, China, ${ }^{2}$ Jiangsu Research Center for Ocean Survey Technology, NUIST, Nanjing, China, ${ }^{3}$ College of Marine Science, University of South Florida, St. Petersburg, Florida, USA, ${ }^{4}$ National Marine Environment Monitoring Center, Dalian, China

\begin{abstract}
Particle-size distribution (PSD), a measure of particle concentrations at different sizes, is of great importance to the understanding of many biogeochemical processes in coastal marine ecosystems. Here, a hybrid method, including analytical, semianalytical, and empirical steps, is developed to estimate PSD through the median diameter of suspended particles $\left(D_{v}^{50}\right)$. Four cruise surveys were conducted to measure optical scattering properties, particle concentrations, spectral reflectance, and particle-size distributions (obtained with a LISST instrument covering a size range of 2.5-500 $\mu \mathrm{m}$ ) in coastal waters of Bohai Sea, Yellow Sea, and Jiangsu coastal region. Based on the Mie scattering theory, $D_{v}^{50}$ is closely related to massspecific backscattering coefficient of suspended particles $\left(b_{\mathrm{bp}}^{*}\right)$, and their relationship is calibrated through a power model $\left(R^{2}=0.796, \mathrm{n}=67, p<0.001\right)$ for the $D_{v}^{50}$ range of $23.5-379.8 \mu \mathrm{m}$. The model is shown to perform better than the previously used inverse-proportion model. The retrieval of $b_{\mathrm{bp}}^{*}$ is through a bio-optical model that links remote sensing reflectance just beneath the surface to inherent optical properties, where a close empirical relationship is established between particulate backscattering and particle concentration. The hybrid method shows high degree of fitting $\left(R^{2}=0.875, \mathrm{n}=46, p<0.001\right)$ between the measured and estimated $D_{v}^{50}$ for the size range of 17.2-325.2 $\mu \mathrm{m}$ used in the model calibration, while validation using two independent data sets shows mean absolute percentage errors of $46.0 \%$ and $64.7 \%$, respectively. Application of the hybrid method to MODIS (Moderate Resolution Imaging Spectroradiometer) data results in spatial distributions of $D_{v}^{50}$ that are generally consistent with those from in situ observations, suggesting potential use of the method in studying particle dynamics through time series of remote sensing observations. However, its general applicability to other regions still requires further research.
\end{abstract}

\section{Introduction}

Particle-size distribution (PSD), a parameter to characterize particles suspended in water, is a measure of particle volume or number concentrations at different sizes [Bader, 1970]. PSD provides important information for investigations on the structure and functioning of aquatic ecosystems, and is thus capable of serving for many oceanographic research [Xi et al., 2014], such as studies of phytoplankton function types, sediment fluxes, resuspension, aggregates, settling rates, and carbon export [Ahn, 2012; Boss and Pegau, 2001; Buesseler et al., 2007; Le Quéré et al., 2005; Mikkelsen and Pejrup, 2001; Twardowski et al., 2001]. Therefore, it is of great interest to obtain PSD characteristics and their variations in both time and space.

At present, PSD information can be obtained from measurements using several field instruments, such as electrical impedance particle sizers (Coulter Counter), particle imaging systems (FlowCAM), and laser diffractometers (LISST) [Anglès et al., 2008; Aurin et al., 2010; Mikkelsen and Pejrup, 2001; Reynolds et al., 2010; Slade and Boss, 2006], which cover the particle size range of several microns to more than a hundred microns. Although these instruments have provided valuable observations from different cruises worldwide in recent years [Barone et al., 2015; Bowers et al., 2007; Fettweis and Baeye, 2015; Hill et al., 2011; Kostadinov et al., 2009; Neukermans et al., 2012; Qing et al., 2014; van der Lee et al., 2009; Xi et al., 2014], the PSD data are still scarce, therefore insufficient in studying large-scale synoptic distributions of PSD and their temporal variations. Such a shortcoming may be overcome with satellite-borne platforms once appropriate algorithms are developed and validated. 


\begin{tabular}{|c|c|c|c|}
\hline Methods & Advantages & Disadvantages & Authors \\
\hline Specific scattering-based method & $\begin{array}{l}\text { Establishing a semianalytical rela- } \\
\text { tionship between } b_{\mathrm{p}}^{*} \text { and } D_{\mathrm{v}}^{50}\end{array}$ & $\begin{array}{l}\text { Limited by the step of deducing } \\
b_{\mathrm{p}}^{*} \text { from } R_{\mathrm{rs}} \text {, since the backscat- } \\
\text { tering ratio }\left(b_{\mathrm{bp}} / b_{\mathrm{p}}\right) \text { is essential- } \\
\text { ly affected by particle sizes } \\
\text { when used as an input of this } \\
\text { method. }\end{array}$ & Bowers et al. [2007] \\
\hline Reflectance band-ratio method & $\begin{array}{l}\text { A simple and easily operated } \\
\text { method, which can be straight- } \\
\text { ly applied to MERIS and MODIS } \\
\text { data }\end{array}$ & $\begin{array}{l}\text { Lack of theoretical explanation, } \\
\text { relatively narrow particle range. }\end{array}$ & Qing et al. [2014] \\
\hline $\begin{array}{l}\text { Retrieval method of parameters of } \\
\text { Junge-distribution model }\end{array}$ & $\begin{array}{l}\text { Suitable for global large-scale } \\
\text { remote sensing; truly retrieving } \\
\text { the distribution of particle sizes }\end{array}$ & $\begin{array}{l}\text { Large retrieval uncertainties in } \\
\text { coastal productive waters; The } \\
\text { "Junge distribution" model } \\
\text { sometimes shows inaccurate } \\
\text { simulation. }\end{array}$ & $\begin{array}{l}\text { Kostadinov } \\
\text { et al. [2009] }\end{array}$ \\
\hline
\end{tabular}

While many remote sensing algorithms have been published and used to map several water constituents, such as chlorophyll a (Chla), total suspended matter (TSM), and chromophoric dissolved organic matter (CDOM), only a few algorithms have been proposed to estimate particle sizes. Bowers et al. [2007] developed a method to estimate the geographical distribution of suspended particle size in the Irish and adjacent seas. This method is firstly based on a quasitheoretical relationship between mass-specific scattering coefficients $\left(b_{\mathrm{p}}^{*}\right)$ and sizes of suspended particles, established through an inverse-proportion function using 16 samples. This is because particle scattering properties are strongly dependent on the particle composition and PSD according to Mie theory [Mie, 1908]. Then, a semianalytical model is used to estimate specific scattering coefficients of suspended particles. This method has been applied to monthly MODIS images in 2006, and revealed spatiotemporal patterns of suspended particle sizes in the southern Irish Sea [van der Lee et al., 2009]. Qing et al. [2014] proposed a simple empirical model to estimate particle sizes in the Bohai Sea, which is based on the reflectance ratio of green $(560 \mathrm{~nm})$ to red $(665 \mathrm{~nm})$ through empirical regression using 40 samples $\left(R^{2}=0.55\right)$.

In the above studies, the median particle diameter of the volume distribution $\left(D_{v}^{50}\right)$, which corresponds to the 50th percentile diameter with a half of accumulated volume concentration [Hill et al., 2011; Reynolds et al., 2010; Xi et al., 2014], was used to represent the PSD. There are also other methods to describe the PSD, such as the commonly used "Junge distribution" model [Boss et al., 2001; Buonassissi and Dierssen, 2010; Neukermans et al., 2012; Reynolds et al., 2010; Twardowski et al., 2001; Xi et al., 2014]. This model can describe the distribution of particle concentrations at different particle sizes, and is expressed as $N^{\prime}(D)=N^{\prime}\left(D_{0}\right)\left(D / D_{0}\right)^{-\xi}$, where $D_{0}$ is a reference particle diameter (in $\mu \mathrm{m}$ ); $N^{\prime}(D)$ and $N^{\prime}\left(D_{0}\right)$ (in $\mathrm{m}^{-3} \mu \mathrm{m}^{-1}$ ) are the differential number concentrations at $D$ and $D_{0} ; \xi$ is the PSD_slope. Based on the "Junge distribution" model, another method was developed to derive the particle size parameters from satellite data [Kostadinov et al., 2009] study. In this method, the parameters $N^{\prime}\left(D_{0}\right)$ and $\xi$ are the retrieved targets that are linked to particle backscattering coefficient spectrum $\left(b_{\mathrm{bp}}(\lambda)\right)$ through Mie theory, where $b_{\mathrm{bp}}(\lambda)$ is retrieved from satellite-derived normalized water-leaving radiance following Loisel et al. [2006].

In summary, three PSD remote sensing methods have been proposed [Bowers et al., 2007; Qing et al., 2014; Kostadinov et al., 2009]. While they have shown success in case studies, certain limitations still exist (Table 1). For instance, the inverse-proportion relationship between $b_{\mathrm{p}}^{*}$ and $D_{\mathrm{v}}^{50}$, defined in Bowers et al. [2007] study, needs further evaluation and recalibration when applied to other regions with different particle characteristics than those from the model development. The reflectance band-ratio method used in Qing et al. [2014] study is purely empirical, thus only applicable to waters with similar particle characteristics. The model of Kostadinov et al. [2009] is based on the assumption that PSD follows the "Junge distribution." However, such an assumption may not be valid for the entire size range, as shown in several previous studies [Buonassissi and Dierssen, 2010; Ceronio and Haarhoff, 2005; Ferry et al., 2015; Xi et al., 2014]. Additionally, large uncertainties are found when applying the Kostadinov et al. [2009] method to coastal and productive oceanic waters. Therefore, developing PSD remote sensing algorithms suitable for optically complex waters is still a necessary and important task. 


\section{CAGU Journal of Geophysical Research: Oceans}

In the present study, we present and analyze data from extensive measurements of scattering properties, particle concentrations, spectral reflectance, and size distributions (obtained with a LISST, covering the size range $2.5-500 \mu \mathrm{m}$ ) in optically complex coastal waters in Bohai Sea, Yellow Sea, and Jiangsu coastal region. The objective of the current study is to develop a method for retrieving PSD in this large study region using satellite ocean color data. The proposed method is hybrid in nature, built upon retrievals of particulate backscattering which can be achieved through algorithm tuning to utilize the near-infrared (NIR) bands and the well-known bio-optical model [Gordon et al., 1988; Lee et al., 1999, 2002], and upon the relationship between scattering characteristics and particle sizes through Mie scattering theory. The hybrid method is evaluated with two independent in situ data sets. Application of the method to MODIS measurements is also demonstrated, together with discussions on its strengths and limitations.

\section{Data and Methods}

\subsection{Study Area and Data Collection}

The data used in this study were collected from four cruises (Figure 1). Two cruises were conducted during November and May 2014 in Bohai Sea (BS) and Yellow Sea (YS), and the other two were carried out in Jiangsu coastal waters (JCW) during October 2013 and 2014. The BS, YS, and JCW are shallow, semienclosed seas with Case II waters (i.e., optical properties dominated by water constituents other than phytoplankton, Morel and Prieur, 1977]. The BS is the largest inner sea in this region, covering a total area of about $77,000 \mathrm{~km}^{2}$. Its average water depth is $18 \mathrm{~m}$, with the maximum depth of about $70 \mathrm{~m}$ in the north of the Bohai Strait, the only passage to the YS [Wei et al., 2004]. The YS has an area about $380,000 \mathrm{~km}^{2}$ with average and maximum depths of about 44 and $140 \mathrm{~m}$, respectively [Feng et al., 1999; He et al., 2004]. The BS receives a huge amount of suspended sediment loads from more than 17 rivers (e.g., the Yellow River). The rapid proliferation of surrounding industries, agriculture, aquaculture, and domestic sewage in the past several decades

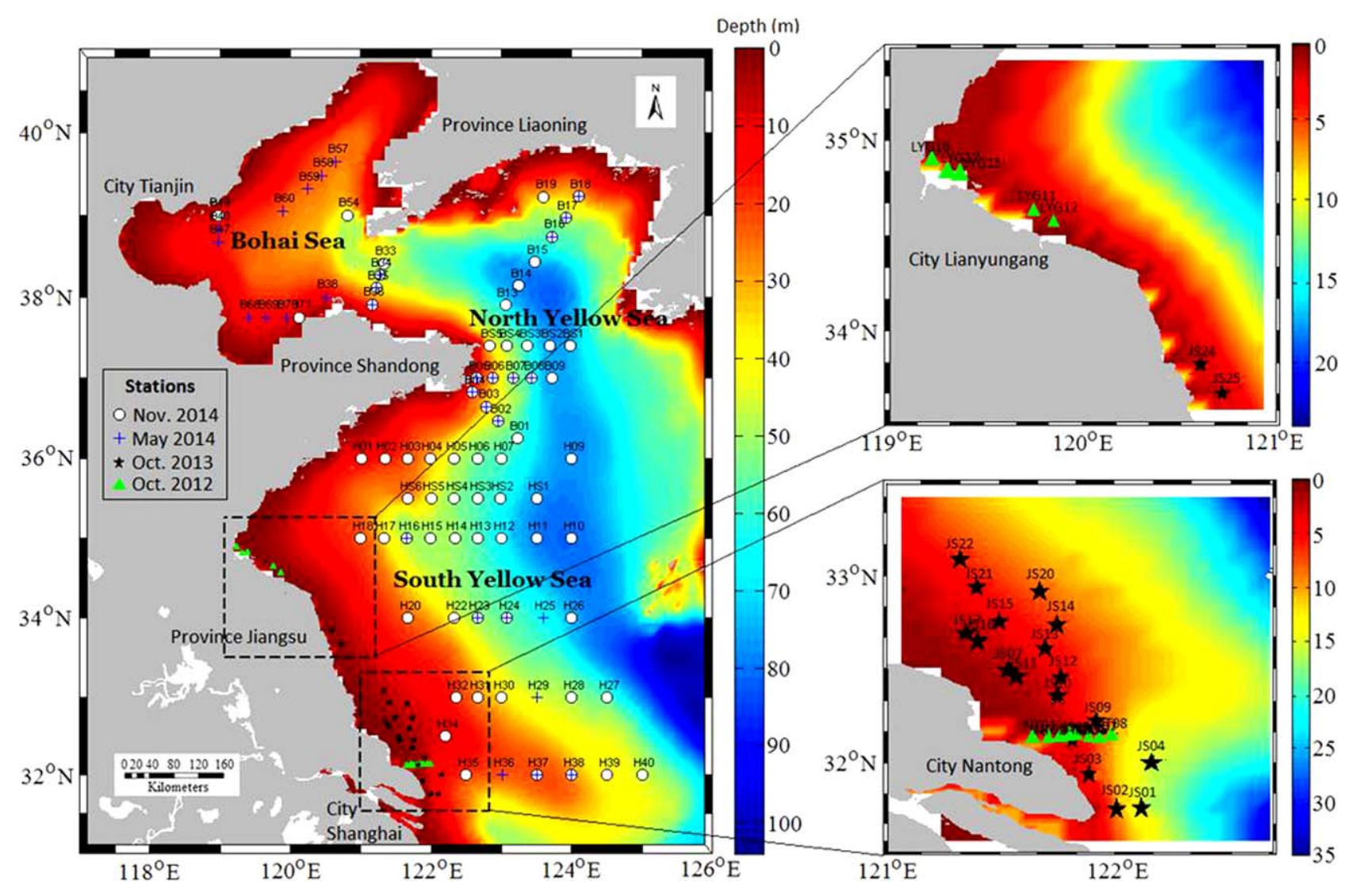

Figure 1. Study area and cruise stations in Bohai Sea, Yellow Sea (including North Yellow Sea and South Yellow Sea, i.e., NYS and SYS), and Jiangsu coastal waters during four cruises in November 2014, May 2014, October 2013, and October 2012, respectively. The colors indicate bathymetry. 
Table 2. Description of Four Cruise Surveys in This Study ${ }^{a}$

\begin{tabular}{llcl} 
Cruise Date & \multicolumn{1}{c}{ Areas } & Stations & \multicolumn{1}{c}{ Measurements } \\
\hline Nov 2014 & Bohai sea and Yellow sea & 67 & $R_{\mathrm{rs}}(\lambda)^{\mathrm{a}}, b_{\mathrm{p}}(\lambda), b_{\mathrm{p}}^{*}(\lambda), b_{\mathrm{bp}}(\lambda), b_{\mathrm{bp}}^{*}(\lambda), \mathrm{TSM}, N(\mathrm{D}), V(\mathrm{D})$, and $D_{\mathrm{v}}^{50}$ \\
May 2014 & Bohai sea and Yellow sea & 35 & $R_{\mathrm{rs}}(\lambda), N(\mathrm{D}), V(\mathrm{D})$, and $D_{\mathrm{v}}^{50}$ \\
Oct 2013 & Jiangsu coastal waters & 20 & $R_{\mathrm{rs}}(\lambda), \mathrm{TSM}, \mathrm{ISM}, \mathrm{OSM}, N(\mathrm{D}), V(\mathrm{D})$, and $D_{\mathrm{v}}^{50}$ \\
Oct 2012 & Jiangsu coastal waters & 14 & $R_{\mathrm{rs}}(\lambda), \mathrm{TSM}, \mathrm{ISM}, \mathrm{OSM}, N(\mathrm{D}), V(\mathrm{D})$, and $D_{\mathrm{v}}^{50}$ \\
\hline
\end{tabular}

a Note that 46 valid samples (not 67 as other parameters) were obtained for $R_{\mathrm{rs}}(\lambda)$ from the November 2014 cruise due to nonoptimal observing conditions.

makes the BS a highly productive yet also polluted water region [Wei et al., 2004]. Similarly, the YS is also influenced by industrial pollution, agricultural runoff, and domestic sewage [Zhang et al., 2010]. Abundant nutrients and sediments from rivers and nonpoint sources exported to the YS, together with the effects of winds and tides lead to low water transparency in the region. The JCW is part of the YS, but the nearshore waters are much more turbid.

The bio-optical measurements were carried out at each station through the use of an optical profiling package mounted with a Sequoia LISST-100X, a WET Labs AC-S, a HOBI Labs Hydroscat-6 (HS-6), and a Seabird SBE49 CTD. This package was slowly lowered in the water column down to a depth just above the bottom. The LISST instrument was used to measure the size spectra of particles of up to $500 \mu \mathrm{m}$ in size, the AC-S was used to measure the scattering coefficients of particles, and the CTD was used to measure the temperature and salinity of the water column. At each station whenever the observing condition was appropriate, reflectance spectra were collected with an ASD FieldSpec spectroradiometer, while water samples were also collected and subsequently analyzed in the laboratory to derive the suspended matter concentrations. The collected bio-optical quantities from the four cruises are summarized in Table 2.

\subsection{LISST Measurement}

The PSD measurements were carried out with a LISST-100X Type-C particle size analyzer. The LISST is a commercially available instrument that measures light scattering of a particle suspension at small forwardscattering angles, and utilizes this information to estimate the PSD [Agrawal and Pottsmith, 2000]. The theoretical foundation is that the optical diffraction by spherical particles whose diameters are significantly larger than the wavelength is assumed equivalent to diffraction by an equal-sized aperture (Fraunhofer diffraction). Many studies have shown that LISST is capable of providing accurate estimates of PSD for various particle suspensions from inland lakes to marine waters [Ahn and Grant, 2007; Anglès et al., 2008; Aurin et al., 2010; Gartner et al., 2001; Karp-Boss et al., 2007; Serra et al., 2001].

The LISST instrument has 32 size ranges logarithmically distributed across a continuous size spectrum from 2.5 to $500 \mu \mathrm{m}$ [Agrawal and Traykovski, 2001; LISST-100X Particle Size Analyzer, 2013]. The upper size in each bin is 1.18 times the lower bin, and the width of individual size classes varies from 0.45 to $76 \mu \mathrm{m}$. Scattered light in the near forward-scattering angles is measured on concentric detector rings, and inversion modeling based on Mie theory yields the particle volume concentration, $V(\mathrm{D})$ (in $\mu \mathrm{L} / \mathrm{L}$ ), in the 32 size bins [Agrawal and Pottsmith, 2000]. For each size bin, there is an equivalent size, $D$ (in $\mu \mathrm{m}$ ), that is assumed to form a volume-equivalent sphere to the unknown particle shape. This is actually the geometric average of the upper and lower sizes of each size bin. Prior to the LISST deployment, a background measurement was carried out with MilliQ water for calibration and subsequent data processing. The $V(D)$ data were derived using the manufacturer-provided software LISST-SOP [LISST-100X Particle Size Analyzer, 2013]. The particle number concentration, $N(D)$ (in counts $\mathrm{m}^{-3}$ ), could be derived by dividing the volume concentration measured for each size bin by the volume of a sphere of the same diameter to obtain numbers of equivalent spherical diameter for each size bin. The inversion equation is

$$
N(D)=6 V(D) / \pi D^{3},
$$

The particle concentrations (volume and number) of each size class within the whole size spectrum could be obtained by this measurement. Each sample would thus have many volume and number concentrations corresponding to different sizes. Using a particle concentration at a discrete size (such as $N(D)$, where $D=37 \mu \mathrm{m}$ ) is one way to show the variability of particle concentrations [Buonassissi and Dierssen, 2010], but 
it only refers to one particle size. This study used the total volume and number concentrations, $V(D)$ and $N(D)$, to represent particle concentrations, which were calculated by summing the quantities of all size bins.

Percentile statistics are often used to describe PSDs, which can be calculated from the various measures of particle sizes, such as volume, number, and projected-area [Reynolds et al., 2010; Xi et al., 2014]. This study calculated the median particle diameter of the volume distribution, $D_{\mathrm{v}}^{50}$, which corresponds to the 50th percentile diameter with a half of accumulated volume concentration. The parameter of $D_{v}^{50}$ carries information of the relative concentration of small to large particles at each station. The greater the $D_{v}^{50}$, the more dominance of large particles, and vice versa.

\subsection{Optical Measurement}

The WET Labs AC-S instrument has a $4 \mathrm{~nm}$ resolution in the range of $400-700 \mathrm{~nm}$, and has a $10 \mathrm{~cm}$ path length. This instrument had been calibrated with Milli-Q ultrapure water before each cruise survey. The raw measurements were corrected for temperature and salinity effects using the method described in WET Laboratories, Incorporated [2013]. The absorption measurements were corrected for the effect of reflective tube scattering following Sullivan et al. [2006]. The direct measurements of the AC-S were the absorption $(a(\lambda))$ and beam attenuation $(c(\lambda))$ for water constituents, which were subsequently used to derive the particle scattering: $b_{\mathrm{p}}(\lambda)=\mathrm{c}(\lambda)-a(\lambda)$. The HS-6 was used to measure particle backscattering, $b_{\mathrm{bp}}(\lambda)$, which was calibrated by the manufacturer before the cruise surveys. It measured scattering at a single angle in the backward direction at about $140^{\circ}$ [Maffione and Dana, 1997], which could be transformed to $b_{\mathrm{bp}}(\lambda)$ through a calibration coefficient. A sigma correction was performed for correcting the path length attenuation effects [HOBI Laboratories, Incorporated, 2012]. The mass-specific scattering and backscattering coefficients, $b_{\mathrm{p}}^{*}(\lambda)$ and $b_{\mathrm{bp}}^{*}(\lambda)$, were calculated by dividing $b_{\mathrm{p}}(\lambda)$ and $b_{\mathrm{bp}}(\lambda)$ by TSM concentrations.

Following the Ocean Optics Protocol [Mueller et al., 2003], the above-water method was used to measure remote-sensing reflectance $\left(R_{\mathrm{rs}}(\lambda)\right)$ in the present study. The ASD FieldSpec spectroradiometer covers a spectral range of 350-1050 nm with an increment of $1.5 \mathrm{~nm}$. The optical fiber detector was kept at about $1 \mathrm{~m}$ above the water surface with a long handle. To avoid the interference of ship shadow and sun glint, the instrument was positioned at an angle of $\varphi_{\mathrm{v}} \sim 135^{\circ}$ relative to the sun and a zenith angle of $\theta_{\mathrm{v}} \sim 40^{\circ}$ when measuring the water and sky radiance. During each measurement, foam patches and whitecaps were avoided. $R_{\mathrm{rs}}(\lambda)$ was derived from these measurements following the Ocean Optics Protocol [Mueller et al., 2003] as:

$$
R_{r s}(\lambda)=\left(L_{t}-r * L_{s k y}\right) /\left(L_{p} * \pi / \rho_{p}\right)
$$

where $L_{\mathrm{t}}$ is the radiance from water; $L_{\text {sky }}$ is the sky radiance; $L_{\mathrm{p}}$ is the radiance measured from a reference panel; $\rho_{\mathrm{p}}$ is the diffuse reflectance of the reference panel (provided by the manufacture); $r$ is the surface Fresnel reflectance, which is a function of wind speed ( $2.2 \%$ for calm weather, $2.5 \%$ for $<5 \mathrm{~m} \mathrm{~s}^{-1}$ wind, 2.6$2.8 \%$ for $10 \mathrm{~m} \mathrm{~s}^{-1}$ wind) [Lee et al., 1996; Mobley, 1999; Tang et al., 2004].

\subsection{TSM Measurement}

Three main steps, including water sample collection, on-site filtration, and weighing in the laboratory, were used to determine TSM concentration from each water sample. The water samples were collected with a Niskin sampler, and then filtered under vacuum onto the preweighed Whatman GF/F filters (47 mm diameter, $0.45 \mu \mathrm{m}$ pore size). The samples were rinsed three times using $50 \mathrm{~mL}$ distilled water to remove dissolved salts. These filters were then preserved in a low-temperature $\left(-20^{\circ} \mathrm{C}\right)$ freezer until the treatment in the laboratory. They were dried in an oven under $40^{\circ} \mathrm{C}$ for $8 \mathrm{~h}$, and weighed after they were put in a glass ware for more than $4 \mathrm{~h}$ restoring to room temperature. Note that the blank and filtered filters were weighed until the difference between two successive TSM measurements from the scale readings were within $0.01 \mathrm{mg}$ $\mathrm{L}^{-1}$. In order to obtain inorganic suspended matter (ISM) and organic suspended matter (OSM), the weighed filters were subsequently placed in a muffle furnace at $500^{\circ} \mathrm{C}$ for $1 \mathrm{~h}$, and then all the organic materials were assumed to be combusted. The filters were reweighed to obtain ISM, and the difference between TSM and ISM was calculated to represent OSM.

\subsection{Satellite Data}

MODIS-Aqua data were used to demonstrate the application of the developed $D_{v}^{50}$ hybrid method in this study. These satellite data were downloaded from the NASA Goddard Space Flight Center (http:// 
oceancolor.gsfc.nasa.gov/, accessed in August 2015, reprocessing \#2014.0). They contain the spectral $R_{\mathrm{rs}}(\lambda)$ data together with the various quality control flags (e.g., atmospheric correction warning, stray light, cloud coverage, etc.), all determined using the most updated calibration and atmospheric correction algorithms. The $1 \mathrm{~km}$ resolution data were used to generate monthly mean $R_{\mathrm{rs}}(\lambda)$ for the periods of November 2013 and November 2014, which were then used with the hybrid method to estimate PSD distributions.

\subsection{Performance Matrix}

Statistical analysis was performed with MATLAB software (MathWorks Inc., Natick, MA, USA) for various biooptical parameters, such as TSM concentrations, particle number concentrations, median particle diameters, the particulate scattering etc. The statistics included minimum, maximum, mean, standard deviation (S.D.), and coefficient of variation (CV). The performance of the developed hybrid method was assessed with determination coefficient $\left(R^{2}\right)$, mean absolute percentage error (MAPE), root mean square error (RMSE), and mean ratio. They were calculated as:

$$
\begin{gathered}
M A P E=\frac{1}{n} \sum_{i=1}^{n}\left|\frac{x_{i}-y_{i}}{x_{i}}\right|(100 \%) \\
R M S E=\sqrt{\frac{1}{n} \sum_{i=1}^{n}\left(x_{i}-y_{i}\right)^{2}} \\
\text { mean ratio }=\frac{1}{n} \sum_{i=1}^{n}\left(\frac{x_{i}}{y_{i}}\right)
\end{gathered}
$$

where $n$ is the number of samples, $x_{\mathrm{i}}$ is the measured value, and $y_{\mathrm{i}}$ is the estimated value.

\section{Results}

\subsection{Bio-Optical Properties}

Table 3 shows the variability of bio-optical parameters, including TSM (in $\mathrm{mg} \mathrm{L}^{-1}$ ), ISM (in mg L ${ }^{-1}$ ), OSM (in $\left.\mathrm{mg} \mathrm{L}^{-1}\right), N(\mathrm{D})$ (in counts $\mathrm{m}^{3}$ ), $D_{\mathrm{v}}^{50}$ (in $\mu \mathrm{m}$ ), $b_{\mathrm{p}}(550)$ (in $\mathrm{m}^{-1}$ ), $b_{\mathrm{p}}^{*}(550)$ (in $\mathrm{m}^{2} \mathrm{~g}^{-1}$ ), $b_{\mathrm{bp}}$ (550) (in $\mathrm{m}^{-1}$ ), $b_{\mathrm{bp}}^{*}(550)$ (in $\mathrm{m}^{2} \mathrm{~g}^{-1}$ ), based on data collected from the four cruises in the BS, YS, and JSW. TSM showed large variability, ranging from 5.5 to $958.0 \mathrm{mg} \mathrm{L}^{-1}$ with a mean of $80.7 \pm 153.1 \mathrm{mg} \mathrm{L}^{-1}$. Correspondingly, $N(D)$ also varied in a wide range with its CV of $342.7 \%$. The median particle diameter (50th percentile) of the volume distribution, $D_{v}^{50}$, ranged between 10.5 and $393.6 \mu \mathrm{m}$ with a mean of $154.1 \pm 106.1 \mu \mathrm{m}$. The particle scattering coefficient, $b_{\mathrm{p}}(550)$, varied between 0.2 and $41.8 \mathrm{~m}^{-1}$, with a mean of $3.0 \pm 6.2 \mathrm{~m}^{-1}$ and a large CV (203.2\%). The mass-specific scattering coefficient, $b_{p}^{*}(550)$, ranged between 0.02 and $0.43 \mathrm{~m}^{2} \mathrm{~g}^{-1}$. The particulate backscattering coefficient, $b_{\mathrm{bp}}(550)$, also showed large variations $(\mathrm{CV}=252.5 \%)$ from 0.001 to $1.298 \mathrm{~m}^{-1}$. The mass-specific backscattering coefficient, $b_{\mathrm{bp}}^{*}(550)$, ranged from 0.001 to $0.014 \mathrm{~m}^{2} \mathrm{~g}^{-1}$, with a mean of $0.003 \pm 0.003 \mathrm{~m}^{2} \mathrm{~g}^{-1}$. Clearly, the study region is highly dynamic in both space and time.

Table 3. Descriptive Statistics of Measured Parameters ${ }^{a}$

\begin{tabular}{llcccccc} 
Variable & \multicolumn{1}{c}{ Units } & Min & Max & Mean & S.D. & CV (\%) & $\mathrm{n}$ \\
\hline TSM & $\mathrm{mg} \mathrm{L}^{-1}$ & 5.5 & 958.0 & 80.7 & 153.1 & 189.7 & 101 \\
ISM & $\mathrm{mg} \mathrm{L}^{-1}$ & 10.2 & 882.0 & 201.8 & 192.3 & 95.3 \\
OSM & $\mathrm{mg} \mathrm{L}^{-1}$ & 1.4 & 76.0 & 16.5 & 15.2 & 34 \\
$N(\mathrm{D})$ & Counts m$^{-3}$ & $3.65 \times 10^{9}$ & $1.06 \times 10^{14}$ & $4.35 \times 10^{12}$ & $1.49 \times 10^{13}$ & 342.7 & 136 \\
$D_{\mathrm{v}}^{50}$ & $\mu \mathrm{m}$ & 10.5 & 393.6 & 154.1 & 106.1 & 68.9 & 136 \\
$b_{\mathrm{p}}(550)$ & $\mathrm{m}^{-1}$ & 0.2 & 41.8 & 3.0 & 6.2 & 203.2 \\
$b_{\mathrm{p}}^{*}(550)$ & $\mathrm{m}^{2} \mathrm{~g}^{-1}$ & 0.02 & 0.43 & 0.15 & 0.12 & 79.5 \\
$b_{\mathrm{bp}}(550)$ & $\mathrm{m}^{-1}$ & 0.001 & 1.298 & 0.078 & 0.197 & 67 \\
$b_{\mathrm{bp}}^{*}(550)$ & $\mathrm{m}^{2} \mathrm{~g}^{-1}$ & 0.001 & 0.014 & 0.003 & 0.003 & 252.5 \\
\hline
\end{tabular}

${ }^{a}$ The mean, range (minimum and maximum), standard deviation (S.D.), variation coefficient (CV), and number of samples ( $n$ ) for each parameter are provided. 


\section{QAGU Journal of Geophysical Research: Oceans}

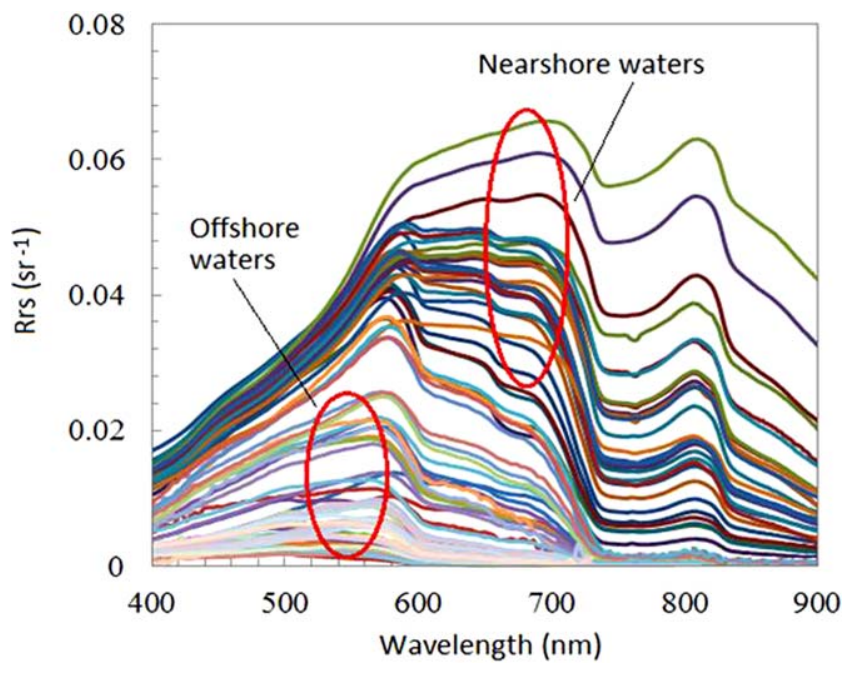

Figure 2. Field-measured $R_{\mathrm{rs}}(\lambda)$ spectra during the four cruise surveys of this study. Note the dramatic differences in both magnitudes and spectral shapes (outlined in red) between nearshore and offshore waters.
Figure 2 shows the field-measured $R_{\mathrm{rs}}(\lambda)$, which also exhibit large variability in both magnitudes and spectral shapes. The $R_{\mathrm{rs}}(\lambda)$ spectra showed typical characteristics of turbid Case II waters such as the low reflectance at $<450 \mathrm{~nm}$ due to absorption by CDOM and phytoplankton, the high reflectance between 580 and $700 \mathrm{~nm}$ due to combined effects of absorption and backscattering of optically significant constituents (OSCs) and water molecules, a local reflectance peak near $815 \mathrm{~nm}$ attributed to relatively smooth NIR particulate backscattering and local water absorption maxima around $750 \mathrm{~nm}$. The reflectance spectra also showed decreased magnitudes from nearshore to offshore waters, corresponding well to the decreased TSM

concentrations. These characteristics are similar to those previously reported in other turbid Case II waters [Dall'Olmo and Gitelson, 2005; Gitelson et al., 2007; Hu et al., 2010a; Lee et al., 1994; Sun et al., 2015a,2015b; Qiu et al., 2014].

\section{2. $D_{\mathrm{v}}^{50}$ Model Development}

\subsubsection{Particle Size Relating to Mass-Specific Scattering and Backscattering}

It is generally acknowledged that the beam attenuation $\left(c_{\mathrm{p}}\right)$, scattering $\left(b_{\mathrm{p}}\right)$, and backscattering $\left(b_{\mathrm{bp}}\right)$ coefficients (units: $\mathrm{m}^{-1}$ ) of suspended particles increase with concentrations [Babin et al., 2003; Boss et al., 2009a]. The mass-specific attenuation $\left(c_{\mathrm{p}}^{*}\right)$, scattering $\left(b_{\mathrm{p}}^{*}\right)$, and backscattering $\left(b_{\mathrm{bp}}^{*}\right)$ coefficients (units: $\mathrm{m}^{2} \mathrm{~g}^{-1}$ ) are expected to vary with particle size and material composition (i.e., refractive index), internal structure, and shape characteristics [Neukermans et al., 2012]. Many theoretical and experimental works have studied the influence of particle size on $c_{\mathrm{p}}^{*}$ and $b_{\mathrm{p}}^{*}$ [Pak et al., 1970; Spinrad et al., 1983; Baker and Lavelle, 1984]. Based on Mie scattering theory, small particles scatter more light than larger ones per unit mass [van de Hulst, 1957; Stramski and Kiefer, 1991]. This is due to (1) the capability of scattering is subject to the particle crosssectional area (units: $\mathrm{m}^{2}$ ). The larger the cross-sectional area, the greater the scattering; (2) the mass concentration is determined by the volume (units: $\mathrm{m}^{3}$ ) under the condition of uniform density. The mass-specific scattering (i.e., scattering per unit mass concentration) should thus be inversely proportional to the diameters of the particles (units: $\mu$ m, i.e., "particle size" in this study) [Bowers et al., 2007]. The mass-specific attenuation would also be influenced by particle size. $c_{\mathrm{p}}^{*}$ and $b_{\mathrm{p}}^{*}$ in open ocean and coastal waters have been reported to vary over one order of magnitude, from 0.05 to $1.5 \mathrm{~m}^{2} \mathrm{~g}^{-1}$ [Baker and Lavelle 1984; Wells and Kim 1991; Gardner et al. 2001; Hill et al. 2011]. $b_{\mathrm{p}}^{*}$ in this study showed a range of $0.02-0.43 \mathrm{~m}^{2} \mathrm{~g}^{-1}$. Although $b_{\mathrm{p}}^{*}$ variations appeared to come from various water bodies, recent work of Boss et al. [2009b] suggested that particulate flocs (i.e., the aggregation process of mineral and organic particles) would lessen its sensitivity to particle sizes. Some investigations also found no large variability in the mass-specific attenuation (or scattering) regarding variations of particle sizes [Bunt et al. 1999; Mikkelsen and Pejrup, 2000]. Rather, relatively tight inverse relationships between $b_{\mathrm{p}}^{*}$ and particle sizes might be present for waters with less particulate flocs [Woźniak et al. 2010]. Thus, it is difficult to establish clear relationships between $b_{\mathrm{p}}^{*}$ and particle sizes by a uniform theoretical method, and accordingly experimental evidence may be a feasible way at the present to quantify such relationships.

Limited field measurements have been conducted to explore the relationships between $b_{\mathrm{p}}^{*}$ and particle sizes. Woźniak et al. [2010] reported a negative power function model to quantify the relationship of $b_{\mathrm{p}}^{*}$ versus $D_{v}^{50}$ in the nearshore waters of Imperial Beach (California). This model showed a good fit for mineraldominated samples $\left(R^{2}=0.82, \mathrm{n}=15\right)$, but the model performance degraded for organic-dominated 

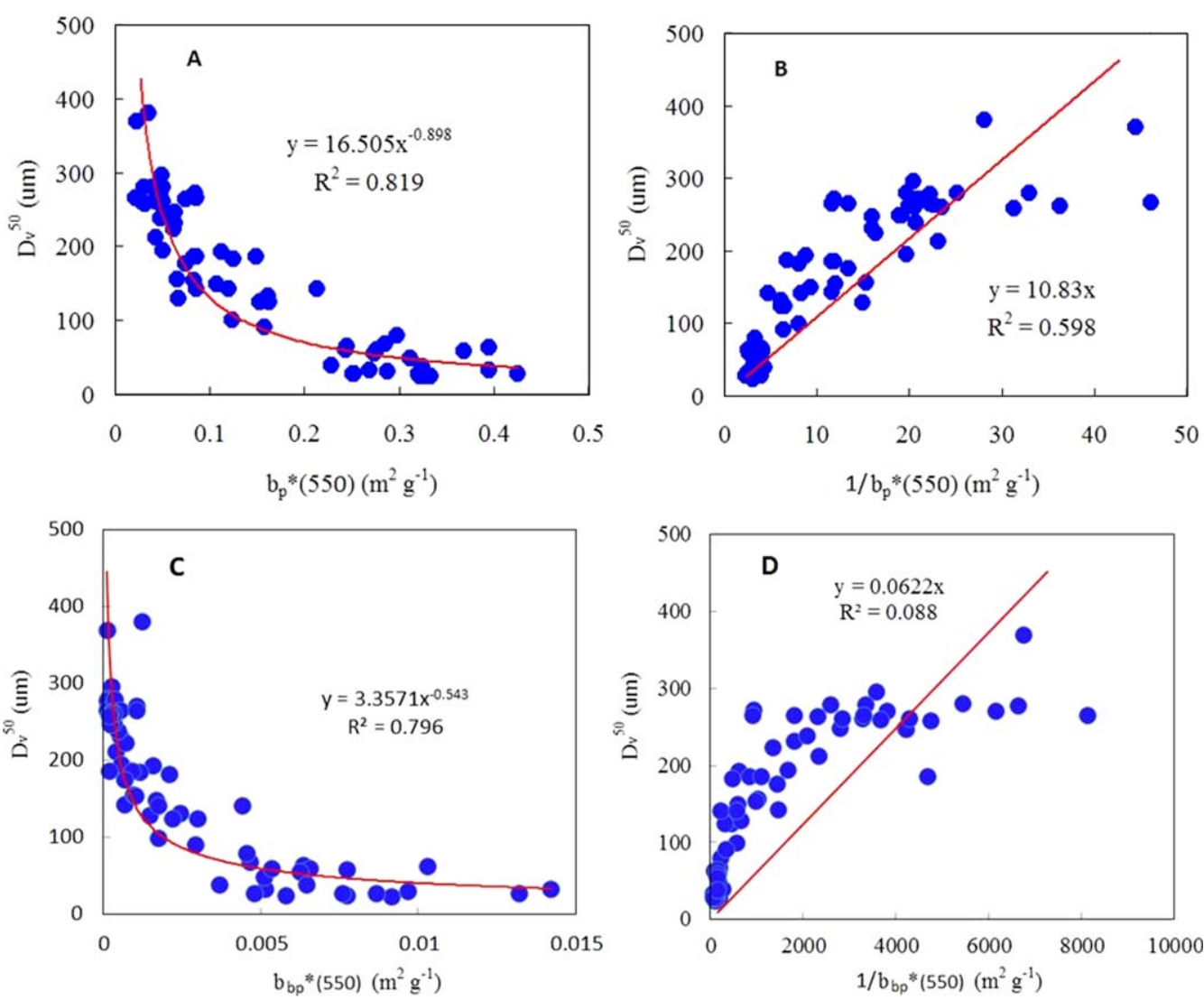

Figure 3. Relationships between $b_{\mathrm{p}}^{*}(550), b_{\mathrm{bp}}^{*}(550)$, and $D_{\mathrm{v}}^{50}$ determined from water samples $(\mathrm{n}=67)$ collected in Bohai Sea and Yellow Sea in November 2014. ( $a$ and c) Negative power function model; ( $b$ and d) Inverse-proportion model. Apparently the relationship is nonlinear. Note that only the relationship in $\mathrm{C}$ is used in this study, while other relationships in Figures $3 \mathrm{a}, 3 \mathrm{~b}$, and $3 \mathrm{~d}$ are for demonstration purpose only.

samples $\left(R^{2}=0.45, \mathrm{n}=8\right)$. Bowers et al. [2007] proposed an inverse-proportion model with a scaling factor to characterize the relationship between $b_{\mathrm{p}}^{*}$ and $D_{\mathrm{v}}^{50}$ by using 16 samples in the Irish and adjacent seas.

In the current study, simultaneous measurements $(\mathrm{n}=67)$ of particle sizes and $b_{\mathrm{p}}^{*}$ and $b_{\mathrm{bp}}^{*}$ were conducted, and the above two models were both tested. As for the relationship of $b_{\mathrm{p}}^{*}$ versus $D_{\mathrm{v}}^{50}$, the determination coefficient $\left(R^{2}\right)$ for the negative power function model was $0.819(p<0.001)$ (Figure 3a), while the inverseproportion model had a $R^{2}$ of $0.598(p<0.01)$ (Figure $\left.3 \mathrm{~b}\right)$. As for the relationship of $b_{\mathrm{bp}}^{*}$ versus $D_{\mathrm{v}}^{50}$, a good fit was also found by the negative power function model $\left(R^{2}=0.796, p<0.001\right)$, while the inverseproportion model showed a less satisfactory result (Figures $3 c$ and $3 d$ ). Overall the parameterization for both models is different from those originally reported for other waters [Bowers et al., 2007; Woźniak et al., 2010], indicating possible differences in not only particle sizes but also particle composition, internal structure, and particle shapes. It is thus important to quantify the regional characteristics in the relationships between $b_{\mathrm{p}}^{*}, b_{\mathrm{bp}}^{*}$ and $D_{\mathrm{v}}^{50}$. The findings here demonstrate that the negative power function model performed reasonably well for our study region, and thus was adopted in our study to model particle-size distributions.

The inverse relationship between mass-specific $b_{\mathrm{p}}^{*}$ (or $b_{\mathrm{bp}}^{*}$ ) and particle size in Figure 3 can be well explained using Mie theory. For a population of spherical particles with identical mean apparent density $\rho_{\mathrm{a}}, b_{\mathrm{bp}}^{*}$ (or $c_{\mathrm{p}^{\prime}}^{*}$ $\left.b_{\mathrm{p}}^{*}\right)$, can be written as:

$$
b_{b p}^{*}=\frac{b_{b p}}{\rho_{a} V C}=\frac{\frac{\pi}{4} \int N(D) Q_{b b}(D, n, \lambda) D^{2} d D}{\rho_{a} \frac{\pi}{6} \int N(D) D^{3} d D}
$$

where $V C$ denotes the volume concentration; $N(D) d D$ is the number of particles per unit volume in the size range from $D$ to $D+d \mathrm{D} ; Q_{\mathrm{bb}}$ is the backscattering efficiency factor (dimensionless), which represents the 
ratio of the backscattering cross section to the geometric cross section. Considering that a particle population is composed of spheres with a uniform diameter $D$, equation (6) can be simplified to equation (7):

$$
b_{b p}^{*}=\frac{3}{2} \frac{Q_{b b}}{\rho_{a} D}
$$

Similar to particle populations, the effective backscattering efficiency, $Q_{\text {bbe }}$ (i.e., mean backscattering efficiency of all particles weighted by area, see equation ((3).2) in Morel 1973; Bowers et al., 2009], and the mean particle diameter weighted by area, $D_{A}$, can be defined by equations (8) and (9)), respectively:

$$
\begin{gathered}
Q_{b b e}=\frac{\int N(D) Q_{b b}(D) D^{2} d D}{\int N(D) D^{2} d D} \\
D_{A}=\frac{\int N(D) D^{3} d D}{\int N(D) D^{2} d D}
\end{gathered}
$$

Then, for particle populations, equation (7) can be rewritten to:

$$
b_{b p}^{*}=\frac{3}{2} \frac{Q_{b b e}}{\rho_{a} D_{A}}
$$

Thus, $b_{\mathrm{bp}}^{*}$ is inversely proportional to particle diameter for spherical particles of identical composition and density [Neukermans et al., 2012]. In other words, large particles have lower backscattering efficiency. This principle has actually been used by Cannizzaro et al. [2008] to differentiate large dinoflagellate Karenia brevis from other phytoplankton. However, in different regions, particle composition and density as well as the relationship between $Q_{b b e}$ and size, wavelength, and refractive index may all change [van de Hulst, 1957], leading to changes in such inverse relationships between $b_{\mathrm{bp}}^{*}$ and particle size. Therefore, as long as these relationships remain relatively stable in one study region, relationship between the $b_{\mathrm{bp}}^{*}$ and particle sizes (equation (5)) may be determined from the in situ data sets through semianalytical model calibration (Figures $3 a$ and $3 c$ ).

\subsubsection{Estimation of Mass-Specific Backscattering From Remote Sensing Reflectance}

According to radiative transfer theory, subsurface remote sensing reflectance, $r_{\mathrm{rs}}(\lambda)\left(\mathrm{sr}^{-1}\right)$, is a function of inherent optical properties (IOPs) including total absorption $a(\lambda)\left(\mathrm{m}^{-1}\right)$ and backscattering $b_{\mathrm{b}}(\lambda)\left(\mathrm{m}^{-1}\right)$ coefficients [Gordon et al.,1988]:

$$
r_{r s}(\lambda)=g_{1}\left(\frac{b_{b}(\lambda)}{a(\lambda)+b_{b}(\lambda)}\right)+g_{2}\left(\frac{b_{b}(\lambda)}{a(\lambda)+b_{b}(\lambda)}\right)^{2}
$$

Then, $b_{\mathrm{b}}(\lambda) /\left(a(\lambda)+b_{\mathrm{b}}(\lambda)\right)$ can be derived from $r_{\mathrm{rs}}(\lambda)$ as

$$
\frac{b_{b}(\lambda)}{a(\lambda)+b_{b}(\lambda)}=\frac{-g_{1}+\sqrt{g_{1}^{2}+4 g_{2} r_{r s}(\lambda)}}{2 g_{2}}
$$

In the equations, $g_{1}$ and $g_{2}$ are wavelength independent constants of 0.0949 and 0.0794 , respectively, for oceanic Case I waters [Gordon et al., 1988] but revised to 0.084 and 0.17 for higher-scattering coastal waters [Lee et al., 1999]. The average values from the two studies were also applied to both coastal and openocean waters [Lee et al., 2002]. The values of $g_{1}$ and $g_{2}$ vary with particle phase function, and therefore need to be determined in order to determine IOPs from $r_{\mathrm{rs}}(\lambda)$. Following Lee et al. [1999], $r_{\mathrm{rs}}(\lambda)$ can be derived from above-surface remote sensing reflectance $R_{\mathrm{rs}}(\lambda)$ :

$$
r_{r s}(\lambda)=\frac{R_{r s}(\lambda)}{0.52+1.7 R_{r s}(\lambda)}
$$

$a(\lambda)$ and $b_{\mathrm{b}}(\lambda)$ can be expressed as

$$
a(\lambda)=a_{w}(\lambda)+a_{p h}(\lambda)+a_{\text {nap }}(\lambda)+a_{c d o m}(\lambda)
$$




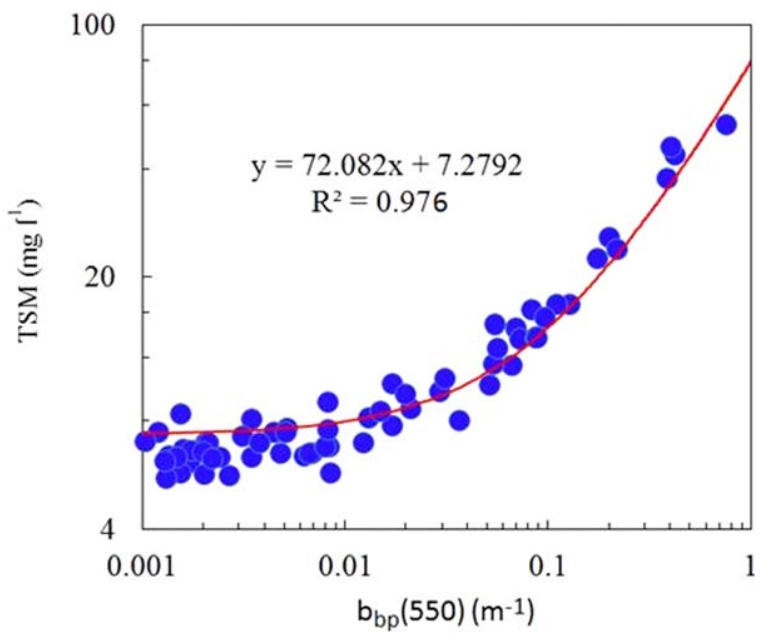

Figure 4. Relationship between $b_{\mathrm{bp}}(550)$ and TSM determined from water samples $(n=67)$ collected in Bohai Sea and Yellow Sea in November 2014

$$
b_{b}(\lambda)=b_{b w}(\lambda)+b_{b p}(\lambda)
$$

where $a_{\mathrm{w}}(\lambda), a_{\mathrm{ph}}(\lambda), a_{\mathrm{nap}}(\lambda)$, and $a_{\mathrm{cdom}}(\lambda)$ are absorption coefficients for pure seawater, phytoplankton pigments, nonalgal particles, and chromophoric dissolved organic matters, and $b_{\mathrm{w}}(\lambda)$ and $b_{\mathrm{bp}}(\lambda)$ are backscattering coefficients for pure seawater and particulate matters, respectively. Considering that $a_{\mathrm{w}}(\lambda)$ in the NIR bands (e.g., 748 and $869 \mathrm{~nm}$ bands of MODIS) is significantly higher than absorption by other constituents for most waters [Babin and Stramski, 2002; Stramski et al., 2007; Tassan and Ferrari, 2003], the following equation can be derived for the NIR wavelengths:

$$
\frac{b_{b}(\lambda)}{a(\lambda)+b_{b}(\lambda)} \approx \frac{b_{b}(\lambda)}{a_{w}(\lambda)+b_{b}(\lambda)}
$$

Accordingly, $b_{\mathrm{bp}}(\mathrm{NIR})$ can be derived from $R_{\mathrm{rs}}(\mathrm{NIR})$ using equations (12), (13), and (16). Then, $b_{\mathrm{bp}}(\lambda)$ in other wavelengths can be derived from $b_{\mathrm{bp}}(\mathrm{NIR})$ using the following power law model [Gordon and Morel, 1983; Snyder et al., 2008; Whitmire et al., 2007]

$$
b_{b p}(\lambda)=b_{b p}\left(\lambda_{0}\right)\left(\frac{\lambda}{\lambda_{0}}\right)^{\eta}
$$

where the slope $\eta$ can be derived by $b_{\mathrm{bp}}(748)$ and $b_{\mathrm{bp}}(869)$ (e.g., for MODIS data). Once $b_{\mathrm{bp}}(550)$ (matching with the green band of HS-6 measurement) was derived using equation (17), the relationship between $b_{\mathrm{bp}}(550)$ and TSM (determined from the in situ samples collected in Bohai Sea and Yellow Sea in November 2014, Figure 4) was used to estimate $b_{\mathrm{bp}}^{*}(550)$ as

$$
b_{b p}{ }^{*}(550)=\frac{1}{72.082+7.2792 / b_{b p}(550)}
$$

\subsubsection{The $D_{\mathrm{v}}^{50}$ Model Development and Calibration}

In summary, Figure 5 presents a schematic flow chart of the hybrid model in this study to derive $D_{v}^{50}$ from $R_{\mathrm{rs}}(\lambda)$. Seven technical steps were included in this process, where the nature of each step, either analytical, semianalytical, or empirical, is annotated in the flow chart. The relationships in S6 and S7 are from empirical regressions (equation (18) and Figure $3 c$ ) based on the in situ measurements in the BS and YS in November 2014, while other steps are from algorithm tuning to utilize the NIR bands and the well-known bio-optical model [Gordon et al., 1988; Lee et al., 1999, 2002].
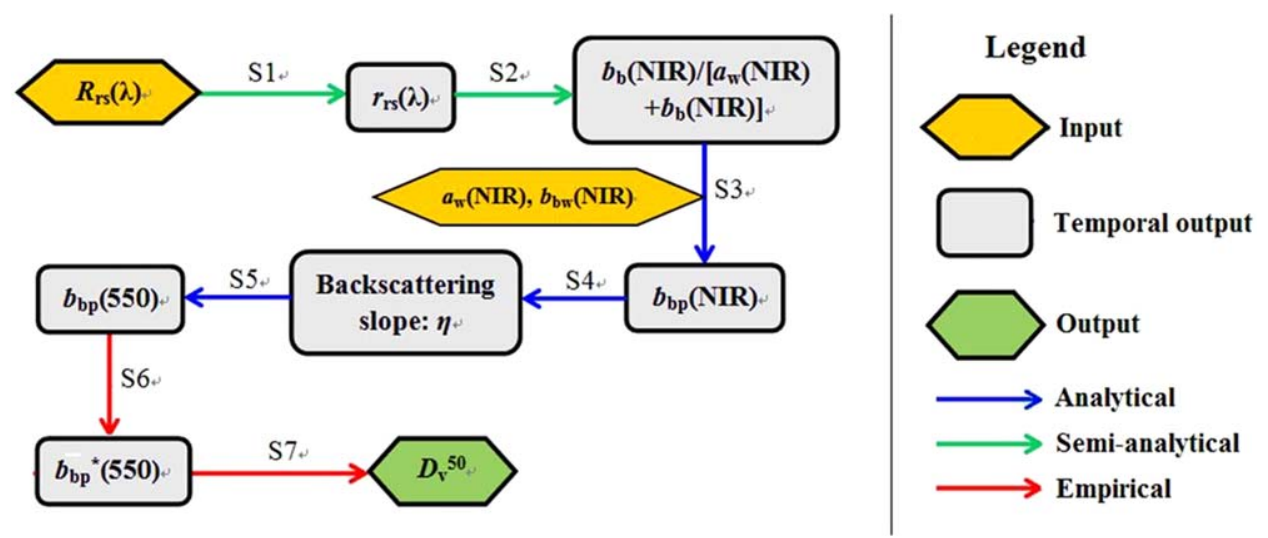

Figure 5. Schematic flow chart showing the developed algorithm for deriving $D_{\mathrm{v}}^{50}$ from $R_{\mathrm{rs}}(\lambda)$. The step numbers are included and written as $\mathrm{Sx}$ where $\mathrm{x}$ ranges from 1 to 7. 


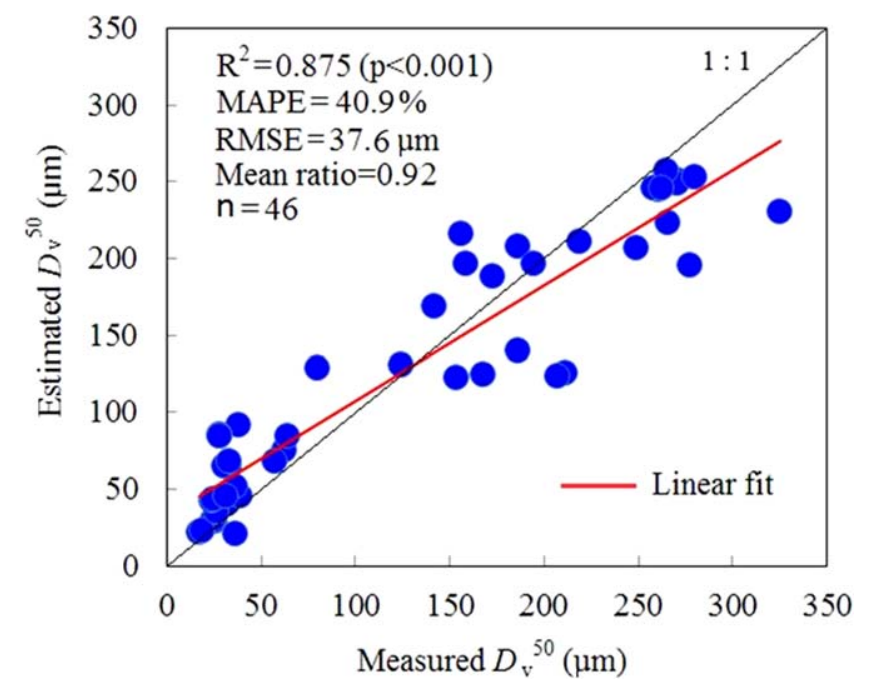

Figure 6. Comparison between measured and estimated $D_{v}^{50}$, where the estimated $D_{v}^{50}$ is from the model-calibration data collected in Bohai Sea and Yellow Sea in November 2014. Note that 46 samples (not 67 as above) were used because the valid reflectance spectra were collected less than the LISST measurements due to nonoptimal observing conditions.
Using the field measured $R_{\mathrm{rs}}(\lambda)$ in the same data set $(n=46)$ collected from the BS and YS in November 2014, $D_{\mathrm{v}}^{50}$ was derived and compared with those determined from the corresponding water samples, with results presented in Figure 6. Although there are some data scattering around the 1:1 line, the coefficient of determination between the measured and $R_{\mathrm{rs}}(\lambda)$-estimated $D_{\mathrm{v}}^{50}$ was relatively high $\left(R^{2}=0.875, p<0.001\right)$. Corresponding MAPE and RMSE were $40.9 \%$ and 37.6 $\mu \mathrm{m}$, respectively. Such a relatively high calibration accuracy is partially attributed to the two empirical relationships specifically tailored for this region, namely $b_{\mathrm{bp}}^{*}(550)$ versus $D_{\mathrm{v}}^{50}$ (Figure $3 c$ ) and $b_{\mathrm{bp}}(550)$ versus TSM (Figure 4). Therefore, independent data are needed to validate the model performance.

\section{3. $D_{\mathrm{v}}^{50}$ Model Validation and Application to MODIS}

To assess the performance of the hybrid $D_{v}^{50}$ model developed in this study, two independent data sets were used, with one collected in the BS and YS $(n=35)$ in May 2014 and another from the Jiangsu coastal waters in October 2012 and $2013(\mathrm{n}=34)$. Both data sets showed high $R^{2}$ values $(>0.81$, with $p<0.001)$, with MAPE being $46.0 \%$ and $64.7 \%$ (Figure 7), respectively. Mean ratios between modeled and measured $D_{v}^{50}$ were close to 1.0 (0.91 and 0.99 , respectively). Most data scattering occurred along the 1:1 line, yes MAPE and RMSE were higher than those in the model calibration (Figure 6), especially for particles $>350$ $\mu \mathrm{m}$ (see circles in Figure 7). This might be due to the absence of large-size samples in the model calibration (Figure 6), yet the errors appeared to be systematic, suggesting that they would not impact the relative spatial or temporal patterns when applied to satellite images.

Such developed $D_{\mathrm{v}}^{50}$ model was applied to MODIS observations corresponding to the two field investigations in November 2013 (not used for model development in this study due to lack of $R_{\mathrm{rs}}$ data) and November 2014. Figure 8 shows two monthly averaged $D_{v}^{50}$ distributions derived from MODIS for the BS and NYS
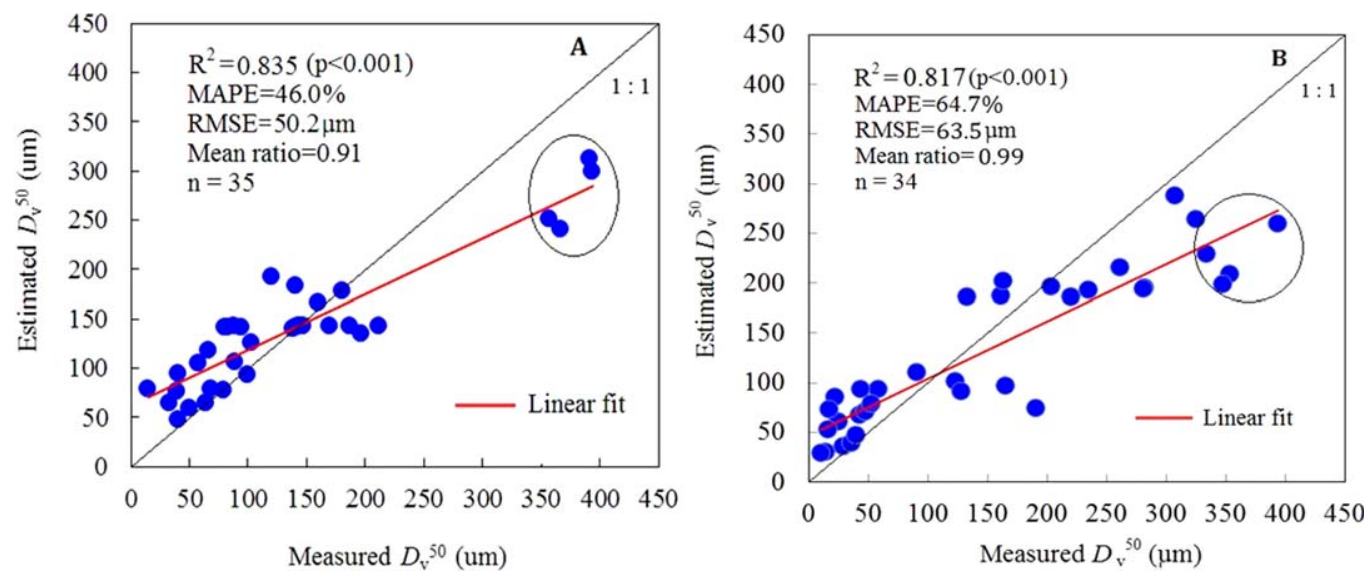

Figure 7. Comparison between measured and estimated $D_{v}^{50}$, where the estimated $D_{v}^{50}$ is from two independent validation data sets. (a) Data collected in the BS and YS in May 2014; (b) data collected in Jiangsu coastal waters in October 2012 and October 2013. Note the underestimation for $D_{v}^{50}>350$ um (circled points), due possibly to the lack of high values in the model development. 
(Figure 8). In November 2013, $D_{v}^{50}$ showed low values of $<\sim 80 \mu \mathrm{m}$ in the BS and nearshore coastal waters, and a general north-south increasing trend in the NYS. The offshore waters in the north of the NYS showed $D_{v}^{50}$ roughly in a range of 100-200 $\mu \mathrm{m}$, with higher values found further south of the offshore waters $(>200$ $\mu \mathrm{m})$. A similar spatial distribution pattern was also found in November 2014 (Figure 8b).

Such MODIS-derived $D_{v}^{50}$ distribution patterns agreed well with those determined from the two field surveys during November 2013 and November 2014 (Figure 9), although the magnitude showed some degree of discrepancy. Note that the in situ data set collected in November 2013 was not used in the model development, thus could be regarded as independent validation. Thus, these results suggest that the proposed hybrid $D_{\mathrm{v}}^{50}$ model may work reasonably well in deriving particle-size distribution patterns from MODIS observations in the study region.

\section{Discussion}

\subsection{Rationality and Limitation of the $D_{\mathrm{v}}^{50}$ Model}

In the current study, a hybrid method was developed to quantify particle-size distribution $\left(D_{v}^{50}\right)$ from satellite measurements over the BS and YS, which essentially depends on the relationship between $b_{\mathrm{bp}}^{*}(550)$
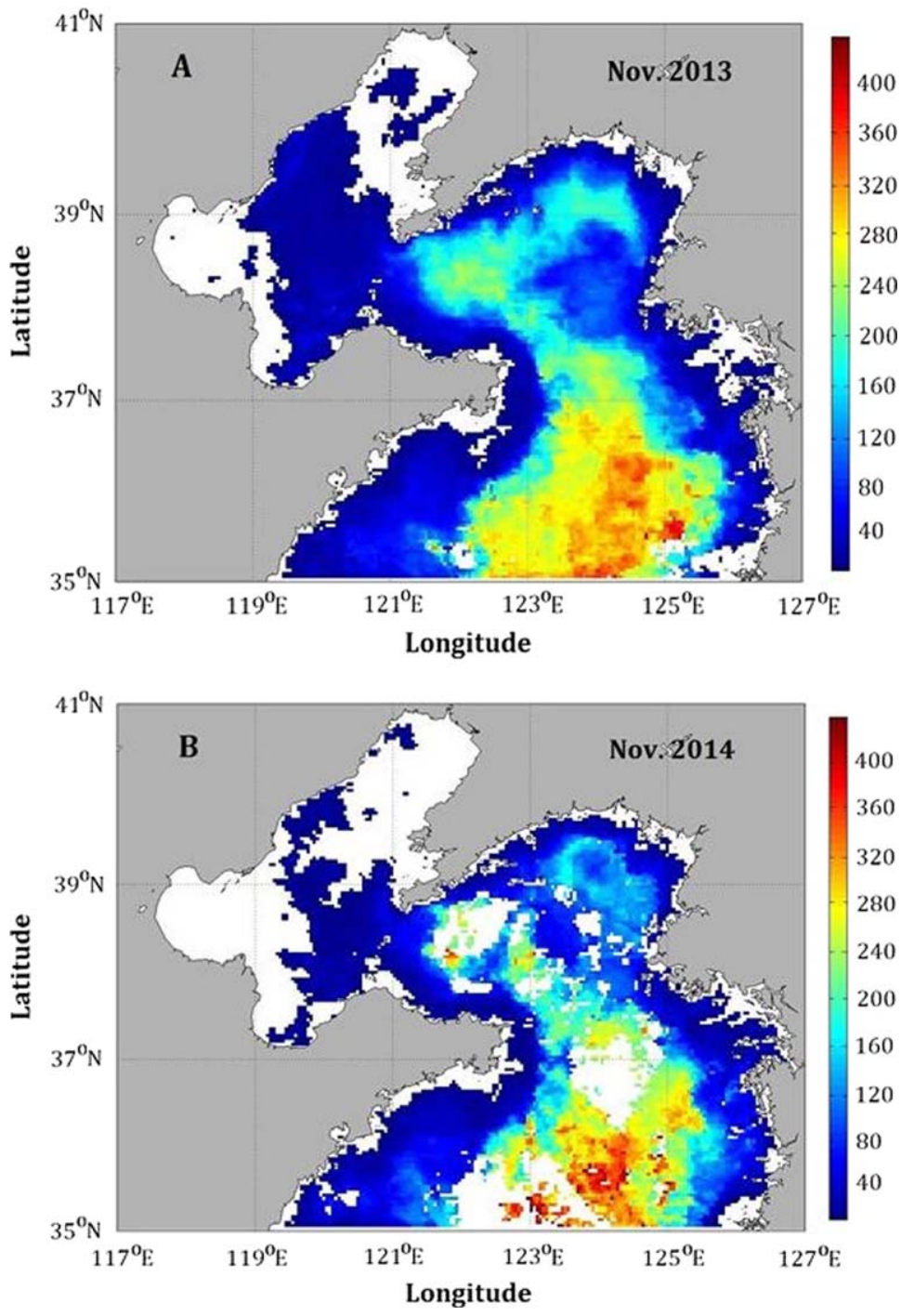

Figure 8. Maps of the $D_{\mathrm{v}}^{50}$ for BS and NYS retrieved from monthly-averaged MODIS Rrs data for (a) November 2013 and (b) November 2014. Gray represents land while white representing missing data due to nonoptimal observing conditions (clouds, thick aerosols, straylight, etc.). and $D_{v}^{50}$ and on the estimation of $b_{\mathrm{bp}}^{*}(550)$. Such a critical parameterization was determined from a number of in situ measurements, which also showed that both $b_{\mathrm{bp}}^{*}(550)$ and $b_{\mathrm{p}}^{*}(550)$ could be used to characterize particle sizes in the study region. Such a finding also confirmed the previous reports for other regions [Bowers et al., 2007, 2009; van der Lee et al., 2009; Woźniak et al., 2010]. On the other hand, the inverseproportion model proposed by Bowers et al. [2007] appeared to perform less satisfactorily than the negative power function model [Woźniak et al., 2010] in our study region after local parameterization. Whether from a theoretical point of view (see Section 3.2.1) or from in situ measurements, close relationships would exist between $b_{\mathrm{bp}}^{*}(550)$, $b_{\mathrm{p}}^{*}(555)$ and $D_{\mathrm{v}}^{50}$. In this study, we used $b_{\mathrm{bp}}^{*}(550)$ instead of $b_{\mathrm{p}}^{*}(550)$ to retrieve $D_{\mathrm{v}}^{50}$, as $b_{\mathrm{p}}(550)$ is considered not retrievable from remote sensing (i.e., remote sensing does not contain information on particle forward scattering). 

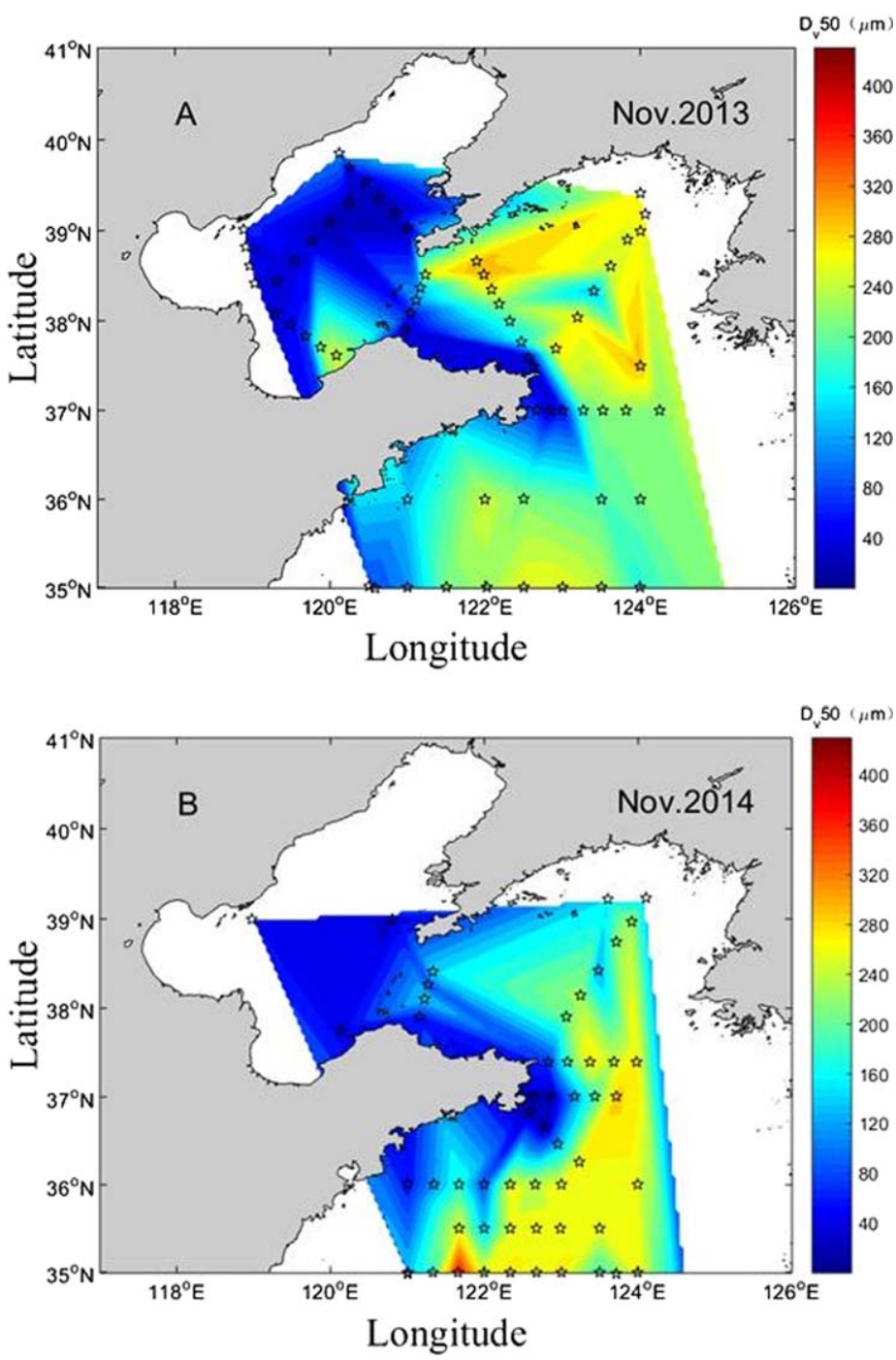

Figure 9. Spatial distribution of $D_{v}^{50}$ in surface waters of BS and NYS, estimated from the in situ data sets collected during (a) November 2013 and (b) November 2014. Stars represent the locations of in situ measurements, which were used for linear interpolation into the whole area by MATLAB software. The color scale is the same to the MODIS color scale in Figure 8.
As the parameterization is primarily from local tuning (e.g., empirical relationship between $b_{\mathrm{bp}}(550)$ and $\left.b_{\mathrm{bp}}^{*}(550)\right)$, there should be limitations on the model's transferability to regions other than the BS and YS. This is because the regional characterization and model inputs may vary among different regions owing to the large diversity and dynamics of the in-water constituents [Babin et al., 2003; Loisel et al., 2007; Snyder et al., 2008; Whitmire et al., 2007; Zhang et al., 2010]. As with any other empirical parameterization, a blind application without local tuning could lead to biased results. However, despite such limitations, the general concept and approach in the hybrid method should still be valid for most waters, and a blind application without local tuning may still yield reasonably well distribution patterns in both space and time even if their absolute values may be subject to large uncertainties.

Compared with the published models, the proposed method has the following characteristics (1) a theoretical foundation and experiment results linking particle sizes to $b_{\mathrm{bp}}^{*}$ instead of $b_{p}^{*}$ for the purpose of remote sensing, as $b_{\mathrm{p}}^{*}$ is not retrievable from remote sensing; (2) appli-

cability to a wider particle size range $(2.5-500 \mu \mathrm{m})$ than reported earlier (e.g., 0-150 $\mu \mathrm{m}$ in Qing et al. [2014]).

Note that although the particle size distribution $\left(D_{\mathrm{v}}^{50}\right)$ derived from the LISST is based on forward scattering measurement, it does show high correlations with backscattering coefficient from either in situ or MODIS observations, suggesting that depending on the study regions LISST may be used to obtain backscattering information that is useful for remote sensing algorithm development.

\subsection{Linkage Between PSD and SIOPs}

$D_{\mathrm{v}}^{50}$ refers to the 50th percentile diameter with a half of accumulated volume concentration below the diameter [Reynolds et al., 2010; Xi et al., 2014], therefore often used to describe PSD. In essence, however, PSD is a series of average numbers of particles under different particle size intervals for a unit volume of suspension [Jonasz and Fournier, 2007; Reynolds et al., 2010; Xi et al., 2014]. Therefore, $D_{v}^{50}$ is simply a ballpark figure for PSD. There are more elaborate methods to describe PSD, such as Junge distribution, Gaussian or lognormal distributions, Weibull distribution, gamma function etc [Bader, 1970; Ceronio and Haarhoff, 2005; Ferry et al., 2015; Jonasz and Fournier, 1996; Risovic, 1993]. Yet it is currently difficult to estimate these 


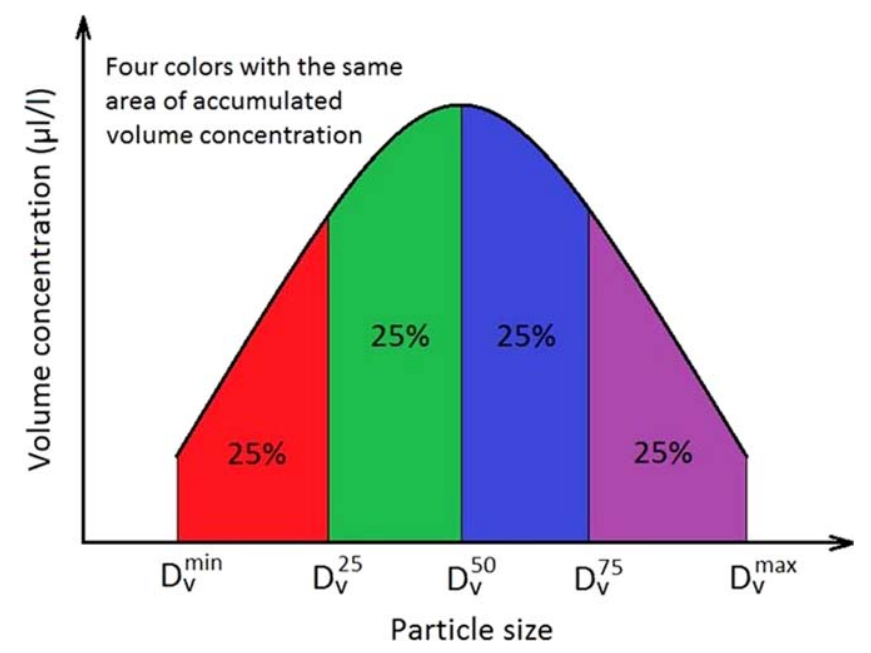

Figure 10. Definitions of $D_{\mathrm{v}}^{25}, D_{\mathrm{v}}^{50}$, and $D_{\mathrm{v}}^{75} \cdot D_{\mathrm{v}}^{\min }$ and $D_{\mathrm{v}}^{\max }$ denote the minimal and maximal particle sizes from the LISST observations, respectively. Red, green, blue, and violet regions represent the accumulated volume concentrations corresponding to the size ranges of $D_{\mathrm{v}}^{\min }-D_{\mathrm{v}}^{25}, D_{\mathrm{v}}^{25}-D_{\mathrm{v}}^{50}, D_{\mathrm{v}}^{50}-D_{\mathrm{v}}^{75}$, and $D_{\mathrm{v}}^{75}-D_{\mathrm{v}}^{\max }$, respectively. $X$ axis denotes particle size, and $y$ axis represents particle volume concentration $(\mu \mathrm{L} / \mathrm{L})$.
PSD functions from satellite remote sensing. In contrast, the retrieval of $D_{v}^{50}$ from remote sensing is more feasible. Similar to $D_{\mathrm{v}}^{50}, D_{\mathrm{v}}^{25}$ (or $D_{\mathrm{v}}^{75}$, Figure 10) can also be used to characterize PSD. Interestingly, from the in situ data sets ( $n=247)$ collected during May and November 2014, $D_{v}^{50}$ showed very close relationships with both $D_{v}^{25}$ and $D_{v}^{75}$ in the current study (Figures $11 \mathrm{a}$ and 11b). This provides supporting information that all three parameters, which are not independent, can be retrieved from satellite remote sensing.

The relationships between $D_{v}^{50}$ and other specific IOPS (SIOPS) were examined, as SIOPS are concentrationnormalized quantities, representing optical properties after subtracting the effect of particle concentrations. As shown in Figure 11c, the mass-specific
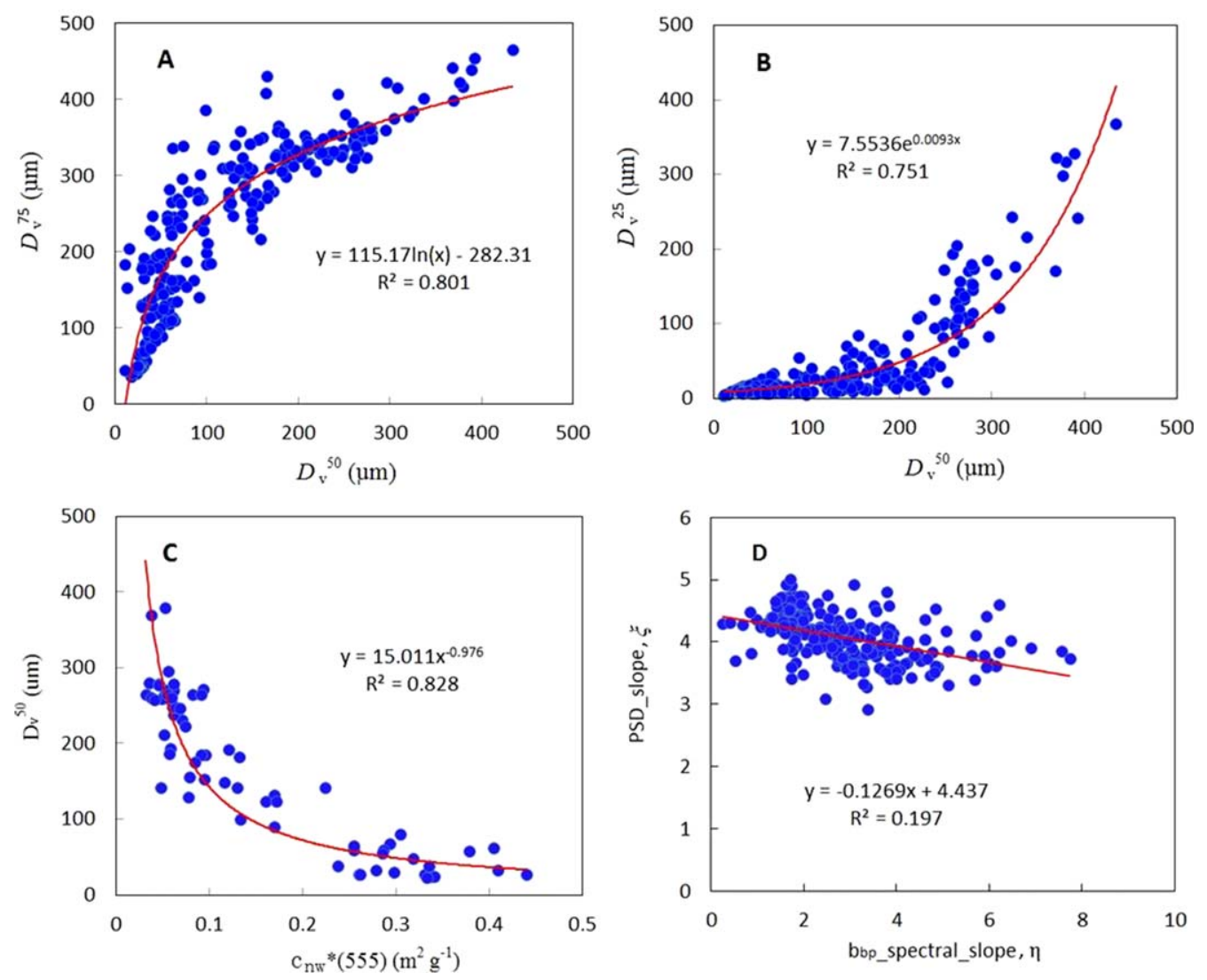

Figure 11. Relationships between $D_{v}^{50}$ and PSD and SIOPs. (a) $D_{v}^{50}$ versus $D_{v}^{75} ;$ (b) $D_{v}^{50}$ versus $D_{v}^{25}$; (c) $D_{v}^{50}$ versus $C_{n w}{ }^{*}(555) ;($ d) PSD_slope ver-

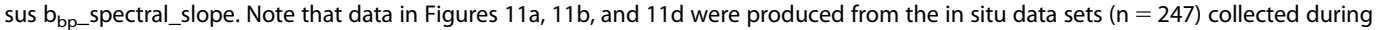
May and November 2014. These data were not restricted to synchronous reflectance data, therefore representing a much larger data set than used above for model calibration and validation. $C$ was formed using the in situ samples $(n=67)$ as in Figure 3. 
nonwater beam attenuation coefficient $\left(c_{n w}{ }^{*}(\lambda)=c_{n w}(\lambda) / T S M\right)$ was found to have a close relationship with $D_{\mathrm{v}}^{50}\left(\mathrm{R}^{2}=0.828, p<0.001\right)$, further supporting the concept of retrieving $D_{\mathrm{v}}^{50}$ using SIOPs.

Another commonly used method for PSD retrievals is through the "Junge distribution" model [Boss et al., 2001; Buonassissi and Dierssen, 2010; Neukermans et al., 2012; Reynolds et al., 2010; Twardowski et al., 2001; Xi et al., 2014]. A key parameter of the model is the PSD slope, $\xi$, which is generally regarded to link PSD with the spectral slope $(\eta)$ of particle backscattering or attenuation coefficients through the equation of $\xi \approx$ $\eta+3$. Boss et al. [2001] introduced a correction by an exponential fit for more general cases of PSD with finite limits. Kostadinov et al. [2009] also found a significant deviation from linearity, and used a thirddegree polynomial fit to represent the relationship between $\xi$ and $\eta$. Here, the relationship between $\xi$ and $\eta$ was analyzed with results shown in Figure $11 \mathrm{~d}$. The lack of tight correlation between the two suggests that it would be difficult to retrieve PSD for the study region through the "Junge distribution" model.

\subsection{Mechanism of $D_{\mathrm{v}}^{50}$ Spatial Variations}

Satellite retrievals and in situ observations showed consistent spatial distribution patterns of $D_{v}^{50}$ in this study. The BS has a shallow bathymetry ( $<30 \mathrm{~m}$ for most areas, and even $<5 \mathrm{~m}$ for nearshore waters) that is prone to sediment resuspension under high winds [Cui et al., 2009, 2010], which also covers the Yellow River estuary, well known for large amounts of suspended sediment discharge [Milliman and Meade, 1983; Wang et al., 2006]. Inorganic minerals and silts thus usually dominate suspended particles in the BS and coastal waters [Qing et al., 2014]. Xu [2006] also reported that sediments of 10-25 $\mu \mathrm{m}$ in size were the main contributors of the Yellow River delta epeirogeny in the YS, where large-sized sediments $(>25 \mu \mathrm{m})$ contributed less, they were more easily deposited in the river course. Hence, fine inorganic particles may explain the low $D_{\mathrm{v}}^{50}$ values in the BS and in most coastal waters. Such spatial patterns are also consistent with the report of Qing et al. [2014].

For offshore regions, terrigenous sediments generally affect less the suspended particulate composition, which is often controlled by phytoplankton. According to several previous investigations [Guo et al., 2013; Hu et al., 2010b; Nie et al., 2014; Wei et al., 2014], dominant algae in the YS are mainly diatoms and dinoflagellates which are microphytoplankton with sizes of $>20 \mu \mathrm{m}$ and up to $1 \mathrm{~mm}$ [Brotas et al., 2013; Stramski et al., 2004]. Accordingly, particle sizes in the offshore YS are usually larger than those in the BS and coastal waters. Furthermore, these also support the observed general trend that $D_{v}^{50}$ gradually increased with increasing distance from shore. In addition, in the center of the YS, the Yellow Sea Warm Current may promote phytoplankton growth [Liu and Wang, 2009; Zhao et al., 2011], leading to higher $D_{v}^{50}$ than elsewhere.

\subsection{Suggestions for Future Work}

The hybrid $D_{v}^{50}$ model developed in the current study is a proof-of-concept for retrievals of particle sizes from satellite ocean color imagery. The essence of this model depends on the close relationships between SIOPs (i.e., specific backscattering of particles) and particle sizes, and on the accurate estimation of SIOPs. The preliminary success presented here is encouraging, and also providing insights on pathways for further improvements.

First, a better parameterization to link PSD with particulate scattering needs to be explored. Particle size is generally deemed as a second-order quantity to influence light scattering [Neukermans et al., 2012; Woźniak et al., 2010]. A close relationship between particle size and $b_{\mathrm{bp}}{ }^{*}(550)$ was found in this study, yet the empirical relationship needs to be further assessed and even recalibrated using more in situ data sets collected from various water types. On a theoretical basis, it is preferred to explore such relationships based on particle characteristics (particle density, composition, size, shape, and structure) and on how these characteristics influence light scattering.

Second, more in situ PSD measurements from various water types are required, as currently the PSD data sets are scarce although it has been realized to be of great significance to many fields of oceanography [Xi et al., 2014]. The PSD measurement protocols need to be improved (1) to cover a broader range of particle sizes from submicron particles to large millimeter-sized flocs that all exist in natural waters [Brotas et al., 2013; Stramski et al., 2004], and (2) to enhance size resolution of detection and capture finer features in the PSD. The current instruments available to the community include electrical impedance particle sizers (Coulter Counter, 1-120 $\mu \mathrm{m}$ ) [Reynolds et al., 2010], particle imaging systems (FlowCAM, 5-100 $\mu \mathrm{m}$ ) [Reynolds et al., 2010], and laser diffractometers (LISST, 1.25-250 $\mu \mathrm{m}$ for Type B and 2.5-500 $\mu \mathrm{m}$ for Type C), but none of them functions over the full optically significant size range [Neukermans et al., 2012]. Note that the LISST 


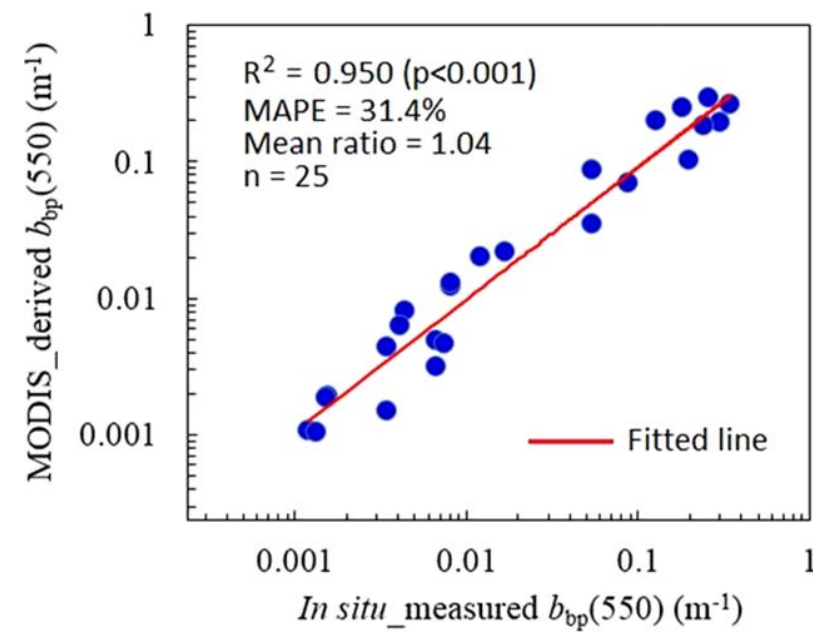

Figure 12. Comparison between field measured and MODIS-derived $b_{\mathrm{bp}}(550)$ $\left(\mathrm{m}^{-1}\right)$ within $\pm 5 \mathrm{~h}$ from the same 25 stations in the BS and YS in November 2014. MODIS $b_{\mathrm{bp}}(550)$ was estimated through Step S1-S5 using a semianalytical model (Figure 5). instrument used in this study measures particles of a wider range than other instruments although its size resolution is lower [Reynolds et al., 2010].

Finally, accurate remote sensing retrievals of $b_{\mathrm{bp}}$ and $b_{\mathrm{bp}}{ }^{*}$ are an essential step in applying the hybrid $D_{\mathrm{v}}^{50}$ method to satellite data. Figure 12 shows the comparison between measured $b_{\mathrm{bp}}(550)$ and MODISderived $b_{\mathrm{bp}}(550)$ within $\pm 5 \mathrm{~h}$ from the same 25 stations in the BS and YS in November 2014. MAPE for the entire data set is $31.4 \%$, comparable to the general $35 \%$ requirement for $\mathrm{Chl}$ retrievals. Most importantly, for the entire data range of $>$ two orders of magnitude, there is no significant bias, as shown by the mean ratio of 1.04 . Deriving $b_{\mathrm{bp}}{ }^{*}$ from $b_{\mathrm{bp}}$, on the other hand, does require local calibration (Figure 4), as the type of TSM may influence such a calibration, especially when large variability in bio-optical properties is expected [Babin et al., 2003; Loisel et al., 2007; Snyder et al., 2008]. Nevertheless, in general, once a calibration relationship between $b_{\mathrm{bp}}{ }^{*}$ from $b_{\mathrm{bp}}$ is established through field work, deriving PSD from satellite measurements using the hybrid $D_{v}^{50}$ method should be straightforward.

The relatively accurate $b_{\mathrm{bp}}(550)$ retrievals from MODIS measurements (Figure 12) are partly due to accurate calibration and atmospheric correction of MODIS data after several rounds of data reprocessing by NASA (reprocessing \#2014.0). Although atmospheric correction is well known to contain errors in turbid coastal waters, most of these errors occur in the blue bands as they have longer distance than other bands from the atmospheric correction bands in the NIR. In this study, the use of blue bands was avoided, thus making the $b_{\mathrm{bp}}(550)$ retrievals relatively accurate to be used in the hybrid method to estimate $\mathrm{D}_{\mathrm{v}}^{50}$. Although we have not tested MODIS $b_{\mathrm{bp}}(550)$ retrievals for other turbid waters, it is speculated that similar results would be obtained because of the relatively accurate atmospheric correction in the green and red bands.

\section{Conclusion}

Existing approaches to remotely estimate PSD yield high uncertainties for the Bohai Sea and Yellow Sea. A hybrid method is developed and validated to estimate PSD in these marginal seas as well as in Jiangsu coastal waters from MODIS measurements. A key step in the hybrid method is to relate particle size to mass-specific backscattering coefficient based on Mie scattering theory, and then to calibrate their relationship through the use of a power model $\left(R^{2}=0.796, \mathrm{n}=67, p<0.001\right.$, for the $D_{\mathrm{v}}^{50}$ range of 23.5-379.8 $\left.\mu \mathrm{m}\right)$. With existing models to retrieve particle backscattering coefficient from remote sensing [Gordon et al., 1988; Lee et al., 1999, 2002], this hybrid method can be applied to MODIS-derived reflectance data to map PSD distributions. Sample results of such an application show general agreement with those determined from in situ observations, where MAPEs from the two independent data sets are $46.0 \%$ and $64.7 \%$, respectively. The findings here demonstrate the feasibility of estimating PSD distributions in optically complex waters through satellite remote sensing and regional optical modeling, while the applicability of the proposed method to other regions needs to be further investigated.

\section{Notation}

PSD particle-size distribution, expressed as $N^{\prime}(D)$, counts $\mathrm{m}^{-3} \mu \mathrm{m}^{-1}$.

$D \quad$ particle size, $\mu \mathrm{m}$.

$D_{\mathrm{v}}^{50:} \quad$ median diameter of suspended particles, $\mu \mathrm{m}$.

$b_{\mathrm{bp}}^{*} \quad$ mass-specific backscattering coefficient of suspended particles, $\mathrm{m}^{2} \mathrm{~g}^{-1}$. 


\begin{tabular}{|c|c|c|}
\hline & Chla & chlorophyll a concentration, $\mathrm{mg} \mathrm{m}^{-3}$. \\
\hline & TSM & total suspended matter concentration, $\mathrm{mg} \mathrm{L}^{-1}$. \\
\hline & CDOM & chromophoric dissolved organic matter. \\
\hline & $b_{\mathrm{p}}^{*}$ & mass-specific scattering coefficient of suspended particles, $\mathrm{m}^{2} \mathrm{~g}^{-1}$ \\
\hline & $D_{0}$ & a reference particle diameter, $\mu \mathrm{m}$. \\
\hline & $N^{\prime}(D)$ & differential number concentrations at $D$, counts $\mathrm{m}^{-3} \mu \mathrm{m}^{-1}$. \\
\hline & $N^{\prime}\left(D_{0}\right)$ & Differential number concentrations at $D_{0}$, counts $\mathrm{m}^{-3} \mu \mathrm{m}^{-1}$. \\
\hline & $\xi$ & the PSD_slope. \\
\hline & $b_{\mathrm{bp}}(\lambda)$ & particle backscattering coefficient at wavelength $\lambda, \mathrm{m}^{-1}$. \\
\hline & $b_{\mathrm{p}}(\lambda)$ & particle scattering coefficient at wavelength $\lambda, \mathrm{m}^{-1}$. \\
\hline & $V(\mathrm{D})$ & particle volume concentration, $\mu \mathrm{L} \mathrm{L}^{-1}$. \\
\hline & $N(\mathrm{D})$ & Particle number concentration, counts $\mathrm{m}^{-3}$. \\
\hline & $a(\lambda)$ & absorption coefficient at wavelength $\lambda, \mathrm{m}^{-1}$. \\
\hline & $c(\lambda)$ & beam attenuation coefficient at wavelength $\lambda, \mathrm{m}^{-1}$. \\
\hline & $R_{\mathrm{rs}}(\lambda)$ & remote-sensing reflectance at wavelength $\lambda, \mathrm{sr}^{-1}$. \\
\hline & ISM & inorganic suspended matter concentration, $\mathrm{mg} \mathrm{L}^{-1}$. \\
\hline & OSM & organic suspended matter concentration, $\mathrm{mg} \mathrm{L}^{-1}$. \\
\hline & $Q_{\mathrm{bb}}$ & backscattering efficiency factor. \\
\hline & $Q_{\mathrm{bbe}}$ & effective backscattering efficiency. \\
\hline & $D_{\mathrm{A}}$ & mean particle diameter weighted by area, $\mu \mathrm{m}$. \\
\hline & $\rho_{\mathrm{a}}$ & mean apparent density of particles, $\mathrm{kg} \mathrm{L}^{-1}$. \\
\hline & $r_{\mathrm{rs}}(\lambda)$ & subsurface remote sensing reflectance at wavelength $\lambda, \mathrm{sr}^{-1}$. \\
\hline & $a_{\mathrm{w}}(\lambda)$ & absorption coefficient of pure seawater, $\mathrm{m}^{-1}$. \\
\hline & $a_{\mathrm{ph}}(\lambda)$ & absorption coefficient of phytoplankton pigments, $\mathrm{m}^{-1}$. \\
\hline & $a_{\text {nap }}(\lambda)$ & absorption coefficient of non-algal particles, $\mathrm{m}^{-1}$. \\
\hline Acknowledgments & $a_{\mathrm{cdom}}(\lambda)$ & absorption coefficient of CDOM, $\mathrm{m}^{-1}$. \\
\hline This research was jointly supported by & $b_{w}(\lambda)$ & backscattering coefficient of pure seawater, $\mathrm{m}^{-1}$. \\
\hline $\begin{array}{l}\text { the National Natural Sclence } \\
\text { Foundation of China ( } 41576172 \text {, }\end{array}$ & $b_{\mathrm{bp}}(\lambda)$ & backscattering coefficient of particulate matters, $\mathrm{m}^{-1}$. \\
\hline
\end{tabular}

41276186, and 41506200), the

Provincial Natural Science Foundation of Jiangsu in China (BK20151526, BK20150914), the Natural Science Foundation of the Jiangsu Higher Education Institutions of China (15KJB170015), the National Program on Global Change and Air-sea Interaction (GASI-03-03-01-01), the Public Science and Technology Research Funds Projects of Ocean (201005030), a project funded by "the Priority Academic Program Development of Jiangsu Higher Education Institutions (PAPD)," and sponsored by Qing Lan Project. We acknowledge the captains, officers, and crews of R/V Dongfanghong 2 for excellent assistance during field sampling and measurements. Data to support this article are available upon request from Zhongfeng Qiu (zhongfeng.qiu@nuist.edu.cn).Special thanks to Shuguo Chen and the group led by Tinglu Zhang in Ocean University of China for their significant contributions on in situ data sampling and analysis. We acknowledge hard works of Yibo Yuan, Xiaojing Shen, Hailong Zhang, Yahui Chen, Yu Huan, and Cong Xiao in the field investigations. We thank two anonymous reviewers for valuable comments and suggestions, which have improved the manuscript.

\section{References}

Agrawal, Y. C., and H. C. Pottsmith (2000), Instruments for particle size and settling velocity observations in sediment transport, Mar. Geol., 168, 89-114.

Agrawal, Y. C., and P. Traykovski (2001), Particles in the bottom boundary layer: Concentration and size dynamics through events, J. Geophys. Res., 106, 9533-9542, doi:10.1029/2000JC900160.

Ahn, J. H. (2012), Size distribution and settling velocities of suspended particles in a tidal embayment, Water Res., 46, 3219-3228, doi: 10.1016/j.watres.2012.03.038.

Ahn, J. H., and S. B. Grant (2007), Size distribution, sources, and seasonality of suspended particles in southern California marine bathing waters, Environ. Sci. Technol., 41, 695-702.

Anglès, A., A. Jordi, E. Garcés, M. Masó, and G. Basterretxea (2008), High-resolution spatiotemporal distribution of a coastal phytoplankton bloom using laser in situ scattering and transmissometry (LISST), Harmful Algae, 7, 808-816, doi:10.1016/j.hal.2008.04.004.

Aurin, D., H. M. Dierssen, M. S. Twardowski, and C. S. Roesler (2010), Optical complexity in Long Island Sound and implications for coastal ocean color remote sensing, J. Geophys. Res., 115, C07011, doi:10.1029/2009JC005837.

Babin, M., and D. Stramski (2002), Light absorption by aquatic particles in the near-infrared spectral region, Limnol. Oceanogr., 47, 911-915.

Babin, M., A. Morel, V. Fournier-Sicre, F. Fell, and D. Stramski (2003), Light scattering properties of marine particles in coastal and open ocean waters as related to the particle mass concentration, Limnol. Oceanogr., 48, 843-859, doi:10.4319/lo.2003.48.2.0843.

Bader, H. (1970), The hyperbolic distribution of particle sizes, J. Geophys. Res., 75, 2822-2830.

Baker, E. T., and J. W. Lavelle (1984), The effect of particle size on the light attenuation coefficient of natural suspensions, J. Geophys. Res., $89,8197-8203$.

Barone, B., R. R. Bidigare, M. J. Church, D. M. Karl, R. M. Letelier, and A. E. White (2015), Particle distributions and dynamics in the euphotic zone of the North Pacific Subtropical Gyre, J. Geophys. Res. Oceans, 120, 3229-3247, doi:10.1002/2015JC010774.

Boss, E., and W. S. Pegau (2001), The relationship of light scattering at an angle in the backward direction to the backscattering coefficient, Appl. Opt., 40, 5503-5507, doi:10.1364/AO.40.005503.

Boss, E., M. S. Twardowski, and S. Herring (2001), Shape of the particulate beam attenuation spectrum and its inversion to obtain the shape of the particulate size distribution, Appl. Opt., 40, 4885-4893, doi:10.1364/AO.40.004885.

Boss, E., et al. (2009a), Comparison of inherent optical properties as a surrogate for particulate matter concentration in coastal waters, Limnol. Oceanogr. Methods, 7, 803-810, doi:10.4319/lom.2009.7.803.

Boss, E., W. Slade, and P. Hill. (2009b), Effect of particulate aggregation in aquatic environments on the beam attenuation and its utility as a proxy for particulate mass, Opt. Express, 17, 9408-9420.

Bowers, D. G., C. E. Binding, and K. M. Ellis (2007), Satellite remote sensing of the geographical distribution of suspended particle size in an energetic shelf sea, Estuarine Coastal Shelf Sci., 27, 457-466.

Bowers, D. G., K. M. Braithwaite, W. A. M. Nimmo-Smith, and G. W. Graham (2009), Light scattering by particles suspended in the sea: The role of particle size and density, Cont. Shelf Res., 29, 1748-1755, doi:10.1016/j.csr.2009.06.004. 
Brotas, V., et al. (2013). Deriving phytoplankton size classes from satellite data: Validation along a trophic gradient in the eastern Atlantic Ocean. Remote Sens. Environ., 134, 66-77.

Buesseler, K. O., et al. (2007), Revisiting carbon flux through the ocean's twilight zone, Science, 316, 567-570, doi:10.1126/science.1137959

Bunt, J. A. C., P. Larcombe, and C. F. Jago (1999), Quantifying the response of optical backscatter devices and transmissometers to variations in suspended particulate matter, Cont. Shelf Res., 19, 1199-1220.

Buonassissi, C. J., and H. M. Dierssen (2010), A regional comparison of particle size distributions and the power law approximation in oceanic and estuarine surface waters, J. Geophys. Res., 115, C10028, doi:10.1029/2010JC006256.

Cannizzaro, J. P., K. L. Carder, F. R. Chen, C. A. Heil, and G. A. Vargo (2008), A novel technique for detection of the toxic dinoflagellate, Karenia brevis, in the Gulf of Mexico from remotely sensed ocean color data, Cont. Shelf Res., 28, 137-158.

Ceronio, A. D. and J. Haarhoff (2005), An improvement on the power law for the description of particle size distributions in potable water treatment, Water Res., 39, 305-313.

Cui, T. W., J. Zhang, Y. Ma, W. Zhao, and L. Sun (2009), The study on the distribution of suspended particulate matter in the Bohai Sea by remote sensing, Acta Oceanol. Sin., 31(5), 10-18.

Cui, T. W., J. Zhang, S. Groom, L. Sun, T. Smyth, and S. Sathyendranath (2010), Validation of MERIS ocean-color products in the Bohai Sea: A case study for turbid coastal waters, Remote Sens. Environ., 114, 2326-2336.

Dall'Olmo, G., and A. Gitelson (2005), Effect of bio-optical parameter variability on the remote estimation of chlorophyll a concentration in turbid productive waters: Experimental results, Appl. Opt., 44(3), 412-422.

Feng, S., F. Li, and S. Li (1999), Atmosphere and ocean, in Introduction of Marine Sciences, pp. 233-267, Higher Ed. Press, Beijing

Ferry, S., J. Zirlewagen, O. Hillebrand, T. Licha, and T. Scheytt (2015), Preliminary results on the dynamics of particles and their size distribution at a Karst spring during a snowmelt event, J. Hydrol., 524, 326-332.

Fettweis, M., and M. Baeye (2015), Seasonal variation in concentration, size, and settling velocity of muddy marine flocs in the benthic boundary layer, J. Geophys. Res. Oceans, 120, 5648-5667, doi:10.1002/2014JC010644.

Gardner, W. D., et al. (2001), Optics, particles, stratification, and storms on the New England continental shelf, J. Geophys. Res., 106, 94739497.

Gartner, J. W., R. T. Cheng, P.-F. Wang, and K. Richter (2001), Laboratory and field evaluations of the LISST-100 instrument for suspended particle size determinations, Mar. Geol., 175, 199-219.

Gitelson, A. A., J. F. Schalles, and C. M. Hladik (2007), Remote chlorophyll-a retrieval in turbid, productive estuaries: Cheapeake Bay case study, Remote Sens. Environ., 109, 464-472.

Gordon, H. R., and A. Morel (1983), Remote Assessment of Ocean Color for Interpretation of Satellite Visible Imagery: A Review, Springer-Verlag, Berlin.

Gordon, H. R., O. B. Brown, R. H. Evans, J. W. Brown, R. C. Smith, K. S. Baker, and D. K. Clark (1988), A semi-analytic radiance model of ocean color, J. Geophys. Res., D93, 10,909-10,924.

Guo, S., J. Sun, H. Zhang, and W. Zhai (2013), Phytoplankton communities in the Northern Yellow Sea in Autumn 2011, J. Tianjin Univ. Sci. Technol., 28(1), 22-29.

He, Y., X. Lu, Z. Qiu, and J. Zhao (2004), Shallow water tidal constituents in the Bohai Sea and the Yellow Sea from a numerical adjoint model with TOPEX/POSEIDON altimeter data, Cont. Shelf Res., 24, 1521-1529.

Hill, P. S., E. Boss, J. P. Newgard, B. A. Law, and T. G. Milligan (2011), Observations of the sensitivity of beam attenuation to particle size in a coastal bottom boundary layer, J. Geophys. Res., 116, C02023, doi:10.1029/2010JC006539.

HOBI Laboratories, Incorporated (2012), HydroScat-6 Spectral Backscattering Sensor USER'S MANUAL (Revision H), Hydro-Opt., Biol., and Instrument. Lab., Inc., Tucson, Ariz.

Hu, C., J. Cannizzaro, K. L. Carder, F. E. Muller-Karger, and R. Hardy (2010a), Remote detection of Trichodesmium blooms in optically complex coastal waters: Examples with MODIS full-spectral data, Remote Sens. Environ., 114, 2048-2058.

Hu, C., D. Li, C. Chen, J. Ge, F. E. Muller-Karger, J. Liu, F. Yu, and M.-X. He (2010b), On the recurrent Ulva prolifera blooms in the Yellow Sea and East China Sea, J. Geophys. Res., 115, C05017, doi:10.1029/02009JC005561.

Jonasz, M., and G. Fournier (1996), Approximation of the size distribution of marine particles by a sum of log-normal functions, Limnol. Oceanogr., 41, 744-754.

Jonasz, M., and G. Fournier (2007), Light Scattering by Particles in Water: Theoretical and Experimental Foundations, Academic, London.

Karp-Boss, L., L. Azevedo, and E. Boss (2007), LISST-100 measurements of phytoplankton size distribution: Evaluation of the effects of cell shape, Limnol. Oceanogr., 5, 396-406.

Kostadinov, T. S., D. A., Siegel, and S. Maritorena (2009), Retrieval of the particle size distribution from satellite ocean color observations, J. Geophys. Res., 114, C09015, doi:10.1029/2009JC005303.

Le Quéré, C., et al. (2005), Ecosystem dynamics based on plankton functional types for global ocean biogeochemistry models, Global Change Biol., 11, 2016-2040, doi:10.1111/j.1365-2486.2005.1004.x.

Lee, Z. P., K. L. Carder, S. K. Hawes, R. G. Steward, T. G. Peacock, and C. O. Davis (1994), Model for the interpretation of hyperspectral remote-sensing reflectance, Appl. Opt., 33, 5721-5732.

Lee, Z., K. L. Carder, R. G. Steward, T. G. Peacock, C. O. Davis, and J. L. Mueller. (1996), Protocols for Measurement of Remote-Sensing Reflectance from Clear to Turbid Waters, SeaWiFS Workshop, Halifax, Canada, 22-25 Oct.

Lee, Z., K. L. Carder, C. D. Mobley, R. G. Steward, and J. S. Patch (1999), Hyperspectral remote sensing for shallow waters. 2. Deriving bottom depths and water properties by optimization, Appl. Opt., 38, 3831-3843.

Lee, Z., K. L. Carder, and R. A. Arnone (2002), Deriving inherent optical properties from water color: A multiband quasi-analytical algorithm for optically deep waters, Appl. Opt., 41, 5755-5772.

Lee, Z. P., B. Lubac, J. Werdell, and R. Arnone (2009), An update of the Quasi-Analytical Algorithm (QAA v5). [Available at http://www.ioccg. org/groups/SoftwareOCA/QAAv5.pdf.]

LISST-100X Particle Size Analyzer (2013), User's Manual Version 5.0, Sequoia Sci., Inc.

Liu, C., and F. Wang (2009), Distributions and intra-seasonal evolutions of the sea surface thermal fronts in the Yellow Sea warm current origin area, Mar. Sci., 33(7), 87-93.

Loisel, H., J.-M. Nicolas, A. Sciandra, D. Stramski, and A. Poteau (2006), Spectral dependency of optical backscattering by marine particles from satellite remote sensing of the global ocean, J. Geophys. Res., 111, C09024, doi:10.1029/2005JC003367.

Loisel, H., X. Mériaux, J.-F. Berthon, and A. Poteau (2007), Investigation of the optical backscattering to scattering ratio of marine particles in relation to their biogeochemical composition in the eastern English Channel and southern North Sea, Limnol. Oceanogr., 52, 739-752.

Maffione, R. A., and D. R. Dana (1997), Instruments and methods for measuring the backward scattering coefficient of ocean waters, Appl. Opt., 36, 6057-6067, doi:10.1364/AO.36.006057. 
Mie, G. (1908), Beiträge zur Optik trüber Medien, speziell kolloidaler Metallö sungen, Ann. Phys., 330, 377-445, doi:10.1002/ andp.19083300302.

Mikkelsen, O., and M. Pejrup (2001), The use of a LISST-100 laser particle sizer for in-situ estimates of floc size, density and settling velocity, Geo Mar. Lett., 20, 187-195.

Mikkelsen, O. A., and M. Pejrup (2000), In situ particle size spectra and density of particle aggregates in a dredging plume, Mar. Geol., 170 , 443-459.

Milliman, J. D., and R. H. Meade (1983), World-wide delivery of river sediment to the oceans, J. Geol., 91(1), 1-21.

Mobley, C. D. (1999), Estimation on the remote-sensing reflectance from above-surface measurements, Appl. Opt., 38(36), 7442-7455.

Morel, A. (1973), Diffusion de la lumière par les eaux de mer; résultats expérimentaux et approche théorique, In Optics of the Sea, Interface, and In-Water Transmission and Imaging, AGARD Lect. Ser. 61, (NATO AGARD, 1973). [The scattering of light by seawater: Experimental results and theoretical approach]

Morel, A., and L. Prieur (1977), Analysis of variations in ocean color, Limnol. Oceanogr., 22, 709-722.

Mueller, J. L., G. S. Fargion, C. R. McClain, S. W. Brown, D. K. Clark, B. C. Johnson, H. Yoon, K. R. Lykke, and S. J. Flora (2003), Ocean Optics Protocols for Satellite Ocean Color Sensor Validation, Revision 5, Volume VI: Special Topics in Ocean Optics Protocols, Part 2. NASA Tech. Memo. 211621, Goddard Space Flight Space Cent., Greenbelt, Md.

Neukermans, G., H. Loisel, X. Mériaux, R. Astoreca, and D. McKee (2012), In situ variability of mass-specific beam attenuation and backscattering of marine particles with respect to particle size, density, and composition, Limnol. Oceanogr., 57(1), 124-144.

Nie, J., Y Liu, Z. Feng, Q. Yang, G. Liu, and J. Fan (2014), Phytoplankton community in the North Yellow Sea in spring and yearly variation, Mar. Environ. Sci., 33(2), 182-207.

Pak, H., G. F. Beardsley, G. R. Heath, and H. Curl (1970), Light-scattering vectors of some marine particles, Limnol. Oceanogr., $15,683-687$.

Qing, S., J. Zhang, T. Cui, and Y. Bao (2014), Remote sensing retrieval of inorganic suspended particle size in the Bohai sea, Cont. Shelf Res., 73, 64-71.

Qiu, Z., Y. Su, A. Yang, L. Wang, Z. Mao, B. Zhou, and S. Chen (2014), An approach for estimating absorption and backscattering coefficients from MERIS in the Bohai Sea, Int. J. Remote Sens., 35(24), 8169-8187.

Reynolds, R. A., D. Stramski, V. M. Wright, S. B. Woźniak (2010), Measurements and characterization of particle size distributions in coastal waters, J. Geophys. Res., 115, C08024, doi:10.1029/2009JC005930.

Risovic, D. (1993), Two-component model of sea particle size distribution, Deep Sea Res., Part 1, 40, 1459-1473.

Serra, T., J. Colomer, X. P. Cristina, X. Vila, J. B. Arellano, and X. Casamitjana (2001), Evaluation of laser in situ scattering instrument for measuring concentration of phytoplankton, purple sulfur bacteria, and suspended inorganic sediments in lakes, J. Environ. Eng., 127(11), 1023-1030.

Slade, W., and E. Boss (2006), Calibrated near-forward volume scattering function obtained from the LISST particle sizer, Opt. Express, 14(8), 3602-3615.

Snyder, W. A., et al. (2008). Optical scattering and backscattering by organic and inorganic particulates in U. S. coastal waters, Appl. Opt., 47, 666-677.

Spinrad, R. W., J. R. V. Zaneveld, and J. C. Kitchen (1983), A study of the optical characteristics of the suspended particles in the benthic nepheloid layer of the Scotian Rise. J. Geophys. Res., 88, 7641-7645.

Stramski, D, and D. A. Kiefer (1991), Light-scattering by microorganisms in the open ocean, Prog. Oceanogr., 28, 343-383.

Stramski, D., E. Boss, D. Bogucki, K. J. Voss (2004), The role of seawater constituents in light backscattering in the ocean, Prog. Oceanogr., 61, 27-56.

Stramski, D., M. Babin, and S. B. Wozniak (2007), Variations in the optical properties of terrigenous mineral-rich particulate matter suspended in seawater, Limnol. Oceanogr., 52, 2418-2433.

Sullivan, J. M., M. S. Twardowski, J. R. V. Zaneveld, C. M. Moore, A. H. Barnard, P. L. Donaghay, and B. Rhoades (2006), Hyperspectral temperature and salt dependencies of absorption by water and heavy water in the $400-750 \mathrm{~nm}$ spectral range, Appl. Opt., 45, 52945309.

Sun, D., C. Hu, Z. Qiu, and S. Wang (2015a), Reconstruction of hyperspectral reflectance for optically complex turbid inland lakes: Test of a new scheme and implications for inversion algorithms, Opt. Express, 23(11), 718-740.

Sun, D., C. Hu, Z. Qiu, and S. Wang (2015b), Estimating phycocyanin pigment concentration in productive inland waters using Landsat measurements: A case study in Lake Dianchi, Opt. Express, 23(3), 3055-3074.

Tang, J. W., G. L. Tian, X. Y. Wang, X. M. Wang, and Q. J. Song. (2004), Methods of water spectra measurement and analysis I: Above water method, J. Remote Sens., 8(1), 37-44.

Tassan, S., and G. M. Ferrari (2003), Variability of light absorption by aquatic particles in the near-infrared spectral region, Appl. Opt., 42, 4802-4810.

Twardowski, M. S., E. Boss, J. B. MacDonald, W. S. Pegau, A. H. Barnard, and J. R. V. Zaneveld (2001), A model for estimating bulk refractive index from optical backscattering ratio and the implications for understanding particle composition in case I and case II waters, J. Geophys. Res., 106, 14,129-14,142, doi:10.1029/2000JC000404.

van de Hulst, H. C. (1957), Light Scattering by Small Particles, 470 pp., John Wiley, N. Y.

van der Lee, E. M., D. G. Bowers, E. Kyte (2009), Remote sensing of temporal and spatial patterns of suspended particle size in the Irish Sea in relation to the Kolmogorov microscale, Cont. Shelf Res., 29, 1213-1225.

Wang, H., Z. Yang, Y. Saito, J. P. Liu, and X. Sun (2006), Interannual and seasonal variation of the Huanghe (Yellow River) water discharge over the past 50 years: Connections to impacts from ENSO events and dams, Global Planet. Change, 50(3-4), 212-225.

Wei, H., J. Sun, A. Moll, and L. Zhao (2004), Phytoplankton dynamics in the Bohai Sea: Observations and modeling, J. Mar. Syst., 44, 233251.

Wei, Y., B. Li, W. Cao, Y. Cai, X. Huang, and Y. Fei (2014), Temporal and spatial variation of phytoplankton species composition and abundances in seawater of radial sand ridges of the south Yellow Sea in 2011, J. Appl. Oceanogr., 33(2), 190-197.

Wells, J. T., and S. Y. Kim (1991), The relationship between beam transmission and concentration of suspended particulate material in the Neuse river estuary, North Carolina, Estuaries, 14, 395-403.

WET Laboratories, Incorporated (2013), Ac Meter Protocol Document (Revision N), WET Labs Inc., Philomath, Oreg.

Whitmire, A. L., E. Boss, T. J. Cowles, and W. S. Pegau (2007), Spectral variability of the particulate backscattering ratio, Opt. Express, 15, 7019-7031.

Woźniak, S. B., D. Stramski, M. Stramska, R. A. Reynolds, V. M. Wright, E. Y. Miksic, M. Cichocka, and A. M. Cieplak (2010), Optical variability of seawater in relation to particle concentration, composition, and size distribution in the nearshore marine environment at Imperial Beach, California, J. Geophys. Res., 115, C08027, doi:10.1029/2009JC005554. 
Xi, H., P. Larouche, S. Tang, and C. Michel (2014), Characterization and variability of particle size distributions in Hudson Bay, Canada, J. Geophys. Res. Oceans, 119, 3392-3406, doi:10.1002/2013JC009542.

$\mathrm{Xu}, \mathrm{J}$. (2006), Variation of sediment flux to the sea in various grain size fractions in relation with the delta accretion of the Huanghe River in China, Acta Oceanol. Sin., 28(3), 88-97.

Zhang, M., J. Tang, Q. Song, and Q. Dong (2010), Backscattering ratio variation and its implications for studying particle composition: A case study in Yellow and East China seas, J. Geophys. Res., 115, C12014, doi:10.1029/2010JC006098.

Zhao, S., F. Yu, X. Diao, and G. Si (2011), The path and mechanism of the Yellow Sea Warm Current, Mar. Sci., 35(11), 73-80. 